\title{
(RE) PENSANDO LOS LUGARES-PATRIMONIO A PARTIR DE UN CASO EN LA LLANURA PAMPEANA ARGENTINA
}

\author{
Andrés Pinassi \\ Universidad Nacional del Sur. Buenos Aires, Rep. Argentina \\ andres.pinassi@uns.edu.ar \\ ORCID iD: https://orcid.org/0000-0003-3648-605X
}

Recibido: 09-12-2019 Aceptado: 20-03-2020

Cómo CITAR ESTE ARTículo/CITATION: Pinassi, Andrés (2020). (Re) pensando los lugares-patrimonio a partir de un caso en la llanura pampeana argentina. Estudios Geográficos, 81 (288), e037. https://doi.org/10.3989/estgeogr.202052.032

\begin{abstract}
RESUMEN: Tanto los lugares como el patrimonio son construcciones sociales inducidas por diferentes actores. Sundblad, en la llanura pampeana argentina, no queda exento de estos mecanismos. Actualmente, se destacan procesos que valorizan historias e identidades, sobre la base de ciertos lugares. En este contexto, los interrogantes de la investigación se presentan en dos esferas: una conceptual, lo que conduce a preguntarnos ¿Qué implican los conceptos de lugar y patrimonio? ¿Podemos hablar de lugarespatrimonio?; y otra empírica, interrogándonos ¿Cuáles son los lugares-patrimonio definidos por los propios residentes de la localidad? ¿Qué usos sociales se pueden identificar? ¿Cuál es su situación actual? ¿Qué tensiones se reflejan en torno a ellos? El objetivo de la investigación es (re) pensar los lugares-patrimonio a partir del caso de Sundblad, desde la mirada de los actuales y ex residentes del pueblo rural. Este trabajo se presenta con un enfoque de investigación mixto, en el que se aplican cuestionarios y entrevistas, se da una observación participante y se analiza bibliografía específica.

Como resultado, se obtiene una clasificación de los lugares-patrimonio según la visión de los habitantes y con base en los usos sociales. Entre las principales conclusiones, se traza un horizonte no muy alentador en torno a estos procesos, que reflejan las características propias de la crisis del campo y las pequeñas localidades. La metodología propuesta pretende configurar un esquema que pueda aplicarse a otras latitudes con características similares, teniendo como fin indagar acerca de aquellos lugares que devienen en patrimonio según la perspectiva de la comunidad.
\end{abstract}

PALABRAS CLAVE: lugar; patrimonio histórico-cultural; procesos sociales; espacio rural; pueblo rural; Sundblad.

\section{(RE) THINKING THE HERITAGE-PLACES FROM A CASE IN THE ARGENTINE PAMPEAN PLAIN}

ABSTRACT: Both places and heritage are social constructions induced by different actors. Sundblad, in argentine pampean plain, is not exempt from these mechanisms.

Currently, processes that value stories and identities are highlighted, based on certain places. In this context, the questions of research are presented in two areas: a conceptual one, which leads us to ask: What do the concepts of place and heritage imply? Can we talk about heritage-places?; and another empirical one, interrogating us: What are the heritage-places defined by residents? What social uses can be identified? What is your situation today? What tensions are reflected around them? The purpose of the research is (re) think of heritage-places from the Sundblad case, from the eyes of current and former residents of the rural village. This work is presented with a mixed research approach, in which questionnaires and interviews are applied, a participant observation is given and analysis of specific literature.

As a result, a classification of the places-heritage is obtained according to the vision of the inhabitants and based on social uses. Among the main conclusions, a not-so-encouraging horizon is drawn around these processes, reflecting the characteristics of the crisis in the countryside and small towns. The proposed methodology aims to set up a scheme that can be applied to other latitudes with similar characteristics, in order to investigate those places that become heritage based on the perspective of the community.

KEYWORDS: place; historical-cultural heritage; social processes; rural space; rural town; Sundblad.

Copyright: ( $\odot 2020$ CSIC. Este es un artículo de acceso abierto distribuido bajo los términos de la licencia de uso y distribución Creative Commons Reconocimiento 4.0 Internacional (CC BY 4.0). 


\section{INTRODUCCIÓN}

El concepto de lugar, como uno de los constructos centrales en la ciencia geográfica, y el de patrimonio, se presentan como elaboraciones socioculturales. Son construcciones inducidas por diferentes actores que operan en distintas escalas geográficas, en torno a un determinado territorio, con ciertos fines e intereses. Entender al patrimonio como lugar, posibilita una perspectiva de análisis diferencial a la versión dominante e instituida, que considera a éste como el legado histórico-cultural y/o natural de una sociedad. Este abordaje diferencial abre nuevos interrogantes que se intentarán responder en este artículo.

La localidad de Sundblad, emplazada en la llanura pampeana argentina, no queda exenta de estos mecanismos socio-espaciales. La situación actual de este pueblo rural $^{1}$ es reflejo de los devenires económicos y políticos que se desarrollaron en el país, dando como resultado un espacio en crisis, en términos demográficos y productivos. En la actualidad, se destacan en el poblado algunos procesos enmarcados en lo que algunos autores han denominado "nueva" ruralidad, entendida aquí como una diversificación funcional (Adamo, 2018) o multifuncionalidad del campo (Castro, 2018), en la que tiene lugar la puesta en valor de determinadas historias e identidades, sobre la base de ciertos sitios históricos o expresiones culturales. Estas dinámicas no solo se producen en el contexto de Argentina, sino que también adquieren representatividad en distintos países latinoamericanos y europeos, en los que por distintos motivos económicos, culturales y/o ambientales, cobran protagonismo adquiriendo determinadas particularidades. Es este sentido, se propone a Sundblad como área de estudio, dado que en el poblado se conjugan ambos escenarios: por un lado, un territorio que atraviesa problemáticas poblacionales y económicas, que se traducen en un estado de abandono y deterioro de los componentes históricoculturales; y por el otro, un proceso de revivificación rural, que se manifiesta a partir de dinámicas incipientes de inducción de valor patrimonial por parte de algunos actores implicados. Dichas iniciativas comenzaron a desarrollarse hace algunos años por parte de un grupo de residentes, que ante la situación de abandono del complejo ferroviario local, deciden presentar un proyecto de ordenanza para legitimarlo como patrimonio municipal. A diferencia de otras localidades de la provincia y del país, el objetivo aquí no fue la patrimonialización inducida por un objetivo económico, como pueden ser disí- miles casos en los que se pretende desarrollar la práctica turística, si no que funcionó como un accionar de resistencia ante la obsolescencia y abandono que atravesaba el sitio.

Estos caracteres posicionan a la localidad como un laboratorio territorial de sumo interés, a la vez que permite realizar un aporte a la disciplina, a partir de los resultados obtenidos que se pueden extrapolar a otros espacios geográficos con características similares y, a su vez, por la metodología propuesta, con potencialidad para ser implementada de manera análoga en latitudes disímiles, como herramienta de análisis para la temática en cuestión. Por otro lado, interesa indagar dichas variables, enmarcando el estudio de caso en un análisis mayor, en torno a la noción de lugar y patrimonio, contribuyendo al debate acerca del concepto de lugares-patrimonio.

A partir de lo expuesto, los interrogantes de la investigación se presentan en dos esferas: 1) por un lado, una conceptual, fundamentando el caso propuesto, lo que conduce a preguntarnos ¿Qué implican los conceptos de lugar y patrimonio? ¿Podemos hablar de lugares-patrimonio?; 2) y por otro, una empírica, acerca del espacio analizado, interrogándonos ¿Cuáles son los lugares-patrimonio definidos por los propios residentes de la localidad? ¿Qué usos sociales se pueden identificar? ¿Cuál es su situación actual? ¿Qué tensiones se reflejan en torno a ellos? A partir de estos cuestionamientos se desprende como objetivo general de la investigación, (re) pensar los lugares-patrimonio a partir del caso de la localidad de Sundblad, emplazada en el noroeste de la provincia de Buenos Aires en la llanura pampeana argentina, desde la mirada de los actuales y ex residentes del pueblo rural.

El trabajo se estructura en cuatro partes: en primer término, se fundamenta a nivel teórico la investigación, indagando acerca de los conceptos de lugar, patrimonio y su integración en los lugares-patrimonio; seguidamente, se plantean los aspectos metodológicos, con el enfoque de la investigación, conjuntamente con las técnicas de recolección de datos primarios; en tercera instancia, se caracteriza a Sundblad como estudio de caso, destacando los principales procesos socioeconómicos que determinaron la situación actual del poblado; luego, se analizan los lugares-patrimonio según la perspectiva de los habitantes, proponiendo una categorización para su abordaje a partir del uso social y destacando un caso particular en el que se reflejan ciertas problemáticas o tensiones; por último, se sintetiza lo analizado a 
partir de cartografía temática elaborada para el caso indagado, según distintas variables propuestas.

\section{LUGAR + PATRIMONIO = ¿LUGARES-PATRIMONIO?}

Como se mencionara, el objetivo de este trabajo es (re) pensar los lugares-patrimonio a partir de un caso de estudio en particular. Asimismo, se pretende profundizar en la línea temática de investigación que se viene desarrollando desde hace unos años, que analiza el patrimonio desde una perspectiva geográfica, poniendo énfasis en los espacios subjetivos de los individuos, más allá de los valores excepcionales como determinantes de la configuración patrimonial.

En palabras de Lindón, Hiernaux y Aguilar (2006) el espacio geográfico puede ser abordado desde diferentes concepciones: con un sesgo naturalista; con un anclaje que enfatice la localización absoluta y/o relativa; con una perspectiva desde la producción material de dicho espacio y, por último, aquel enfoque que lo hace desde el espacio vivido-concebido. Es desde esta última esfera, que se toma posicionamiento para abordar el concepto de lugar y su relación con el patrimonio cultural.

El lugar como constructo clave en la ciencia geográfica adquiere relevancia en las décadas de 1960 y 1970 en el ámbito de la geografía humanista. En el mundo anglosajón cobran protagonismo los aportes de Yi Fu Tuan y Anne Buttimer, poniendo énfasis en la carga emotiva y sentimental y en las representaciones que las personas construyen en torno a determinados espacios, deviniendo éstos en lugares, a partir de dicha inducción de valor social (Lindón, 2006; Torres, 2011; Benedetti, 2017). Desde esta mirada "... el lugar es concebido como un área limitada, como una porción concreta del espacio con una carga simbólica y afectiva" (Nogué, 1989, p. 69). Es decir, que los individuos construyen socialmente los lugares a través de su espacialidad y en relación con los vínculos sociales en una determinada localidad. Desde esta mirada, el lugar se posiciona como espacio-fortaleza, como punto de defensa de la identidad, de lo local, excluyendo todo aquello que acontece fuera del mismo. Se marginan así las relaciones de poder y las posibles tensiones que puedan generarse, y se asume una connotación de uniformidad de los individuos, en términos sociales, económicos y culturales (Benedetti, 2017).

A partir de la década del ' 80 emergen miradas alternativas en torno a la noción de lugar, con una connotación diferencial a la de raíz fenomenológica enmarcada en la geografía humanista. En este ámbito, se cambia el anclaje netamente local para colocar a la configuración de los lugares en un juego de escalas geográficas. Desde esta postura, el lugar se elabora socialmente no solo por lo que sucede en la escala local, sino también por aquellas relaciones y procesos que se dan con otras escalas mayores (Benedetti, 2017). En esta construcción social multiescalar entra en juego también la identidad, que al igual que el lugar, desde esta perspectiva alternativa, va a ser definida por las vinculaciones internas y externas que se producen en torno al mismo. Massey destaca al respecto

... que la especificidad de cada lugar es el resultado de la mezcla distinta de todas las relaciones, prácticas, intercambios, etc. que se entrelazan dentro de este nodo y es producto también de lo que se desarrolle como resultado de este entrelazamiento. Es algo que yo he denominado 'un sentido global de lugar', un sentido global de lo local (Massey, 2004, p. 79).

Podríamos decir que esta manera de comprender el lugar determina una serie de beneficios o ventajas con relación a la mirada tradicional, que versan en torno a una postura más dinámica y abierta del concepto, quebrando las fronteras del hermetismo de lo meramente local; por otro lado, la multiplicidad de vinculaciones que intervienen en su definición, lleva a interpelar su ubicación en el espacio ¿Los lugares son localizaciones absolutas y puntuales? ¿O configuran áreas que se superponen?; por último, esta forma alternativa de entender a los lugares, posibilita el análisis de tensiones y posibles problemáticas que puedan suceder en torno al proceso de elaboración social de los mismos (Barros, 2000). Desde dicha postura, los lugares funcionan como foco de interrelaciones entre los hechos globales y la experiencia individual (Nogué, 2014).

Una vez definidas las diferentes miradas acerca del concepto de lugar, interesa plantear qué es lo que entendemos por patrimonio cultural, para poder establecer una serie de vinculaciones entre ambos conceptos y aportar a la compresión de lo que Hammen, Lulle y Palacio (2009) denominan como lugares-patrimonio.

Al igual que el concepto de lugar, el de patrimonio en general y el de cultural en particular, puede abordarse desde diferentes aristas. En el contexto contemporáneo, predomina una postura de análisis que pone su eje en los elementos materiales e inmateriales producto de una cultura, como patrimonios sus- 
ceptibles de valorización. Es así que los componentes históricos adquieren la connotación de legado o herencia del pasado que debe salvaguardarse para las futuras generaciones. Esta es la línea de trabajo de organismos con injerencia a nivel internacional que han contribuido en la difusión de estos preceptos, siendo adoptados por un importante número de académicos y gestores del patrimonio. Es así que la UNESCO (Organización de las Naciones Unidas para la Educación, la Ciencia y la Cultura) referencia un patrimonio mundial o de la humanidad sedimentado sobre la base de los "valores universales excepcionales", como cualidades únicas determinantes de tal legitimación. Más allá de indagar cuáles son los atributos que deben reunir los componentes para ser reconocidos como tal, cabe preguntarnos quién define estos caracteres, con qué objetivos, en qué contexto adquieren relevancia y qué sucede con aquellos componentes que no los reúnen: ¿No son patrimonio? ¿Quién lo establece?

Por otro lado, existen otros posicionamientos que complejizan la mirada patrimonial, poniendo énfasis en los procesos de patrimonialización inducidos por diferentes actores sociales, principalmente aquellos de carácter político, económico y científico, con cierto poder de representatividad. En estos mecanismos los mensajes construidos por los agentes hegemónicos cobran protagonismo como creadores de identidades. Así se elaboran discursos patrimoniales autorizados (Smith, 2011), que representan una realidad e ideología recortada, la de las voces dominantes. En esta línea de trabajo se destacan los aportes de diferentes autores (Arantes, 1984; García Canclini, 1989; Florescano, 1993; Prats, 1997, 1998, 2005, 2006, 2014; Durham, 1998; Rosas Mantecón, 2005; Bertoncello, 2008, 2010, 2017, 2018; Smith, 2011; Velho, 2013; Zusman y Pérez Winter, 2018; Pinassi, 2018; Pinassi y Silenzi, 2019), que han focalizado su análisis en los mecanismos sociales de activación patrimonial (Prats, 1997, 1998, 2005), más allá de profundizar en las particularidades de los componentes culturales y/o naturales intervinientes. Discursos, intereses, actores y tensiones producidas en torno a los mismos, son el eje de estudio de este enfoque alternativo.

Asimismo, también existen otras perspectivas de análisis que se focalizan en aquellos actores sociales marginados, como pueden ser los habitantes de una comunidad y las organizaciones que los mismos integran, que en la mayoría de los casos, adquieren un rol secundario en los procesos sociales de inducción patrimonial, pero que desde su espacio vivido pueden aportar al entendimiento y a la generación de nuevas miradas en torno a la historia y cultura de una localidad. Es así que aparecen categorías específicas, con un fuerte sesgo geográfico, como la de espacio vivido patrimonial $^{2}$ (Pinassi, 2016, 2017, 2019), en la que la valoración, identificación y aprehensión social con respecto a los componentes culturales adquiere un papel central; o el concepto de patrimonios afectivos (Behling Oliveira y Lemos Ribeiro, 2019), en el que la subjetividad ligada a los sentimientos de las personas cobra representatividad en relación a determinados bienes o manifestaciones socioculturales. En esta misma línea, también se destacan los discursos patrimoniales no autorizados, propuestos por Giop y Flores (2017) de manera antagónica a la denominación de Smith (2011), referenciada anteriormente, que aluden en este caso a la representatividad de las voces de los actores sociales marginados en los procesos de patrimonialización. En términos generales, estas miradas alternativas que enfatizan en el sujeto y su relación con los bienes culturales, pueden sintetizarse en lo establecido por Cabrales Barajas, quien expresa que "la clave estriba en colocar al ciudadano en una posición central, de lo cual se desprende una regla de oro: el patrimonio tiene sentido en la medida en que es socialmente valorizado y defendido colectiva o comunitariamente" (Cabrales Barajas, 2019, p. 3).

En esta interrelación entre las diferentes formas de entender el patrimonio y el lugar, emerge un concepto integrador: el lugar-patrimonio. Hammen, Lulle y Palacio expresan que el patrimonio se presenta "... como una emergencia socioespacial dinámica que es construida colectivamente a partir de una multiplicidad de prácticas y representaciones que convergen en un lugar y que muchas veces se encuentran en tensión. Este proceso lo hemos denominado 'lugarpatrimonio'” (Hammen, Lulle y Palacio, 2009, p. 64). En estos lugares-patrimonio se conjugan entonces dos esferas: las patrimoniales y aquellas geográficas relativas al lugar (Fig. 1). En este sentido, los aportes de la geografía humanística, a partir de su base fenomenológica, contribuyen al entendimiento de la construcción del lugar desde la sociedad local, de las vivencias y experiencias de los sujetos en relación con ciertos sitios o componentes históricos de una determinada localidad. Esto permite echar luz sobre aquellas voces marginadas en los procesos de patrimonialización. Por otro lado, la contribución de las geografías posmodernas, radica en el abordaje cultural de estos mecanismos de construcción del lugar-patrimonio, que con una mirada crítica, enfatiza en las tensiones y conflictos que puedan derivarse de las relaciones 
de poder entre los actores intervinientes en distintas escalas geográficas. En síntesis, los lugares-patrimonio se estructuran en un doble juego, entre lo local y lo global, considerando por un lado, el pensar, sentir y vivir de la sociedad local respecto a los componentes histórico-culturales (espacio vivido patrimonial), y por el otro, la relación con aquellos procesos de patrimonialización que se impulsan desde otras escalas, por actores sociales dominantes que escapan al espacio de vida cotidiano. Esto permite desarticular la idea de lugar refugio-fortaleza para posicionarnos en lo que podríamos denominar lugares patrimoniales permeables. Esta integración de relaciones, localextra local, pone en tensión a los componentes patrimoniales, entendidos en sentido amplio, y sus múltiples vínculos sociales, todo ello en relación con el contexto sociocultural, político y económico imperante.

FIGURA 1

CONFIGURACIÓN DE LOS LUGARES-PATRIMONIO

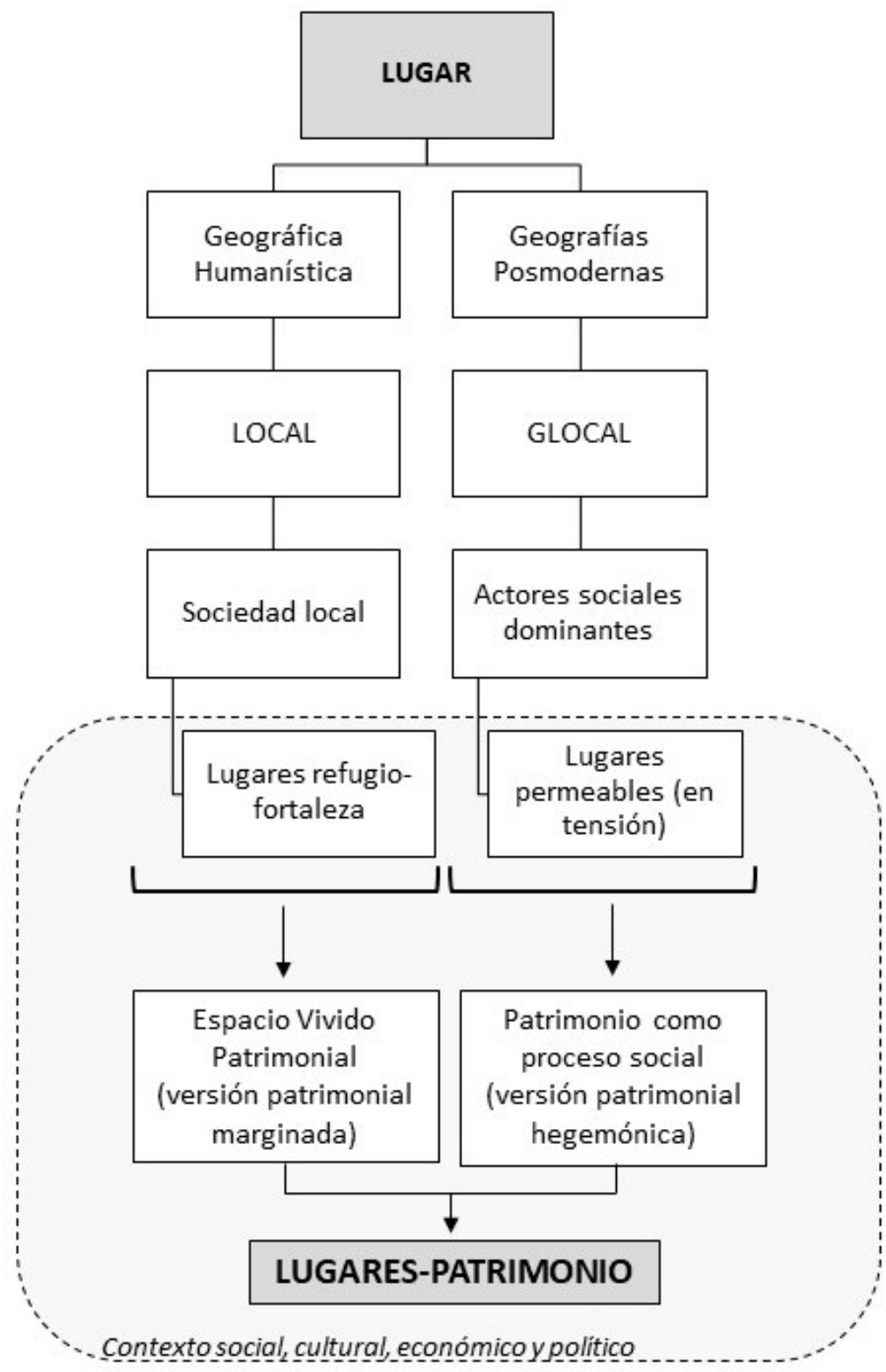

Fuente: Elaboración propia (2020) 
En este ámbito, los lugares-patrimonio constituyen un campo fecundo de análisis, disímil a la producción científica existente en torno a este tema. Escapa del abordaje tradicional que brega por el estudio de los valores materiales, paisajísticos e históricos de un bien patrimonial, para posicionarse en la vinculación con los procesos y actores sociales que le dan sentido y lo construyen como tal.

\section{ASPECTOS METOdológICOS DE LA INVESTIGACIÓN}

En relación a los aspectos metodológicos (Fig. 2), la investigación se plantea desde un enfoque mixto, en el que se articulan herramientas de corte cualitativo con aquellas cuantitativas, a fin de poder obtener un panorama más acabado de la realidad local en torno a los lugares del patrimonio cultural de Sundblad.

En el trabajo de campo, desarrollado entre los meses de julio y octubre de 2019 , se emplearon las siguientes técnicas de recolección de datos, que se determinaron de acuerdo al objetivo de la investigación. Si bien se es consciente que se pueden indagar otras miradas que permitan comprender los procesos de construcción de los lugares-patrimonio desde un enfoque disímil al aquí propuesto, como son los discursos de los actores sociales hegemónicos, en esta etapa se ha priorizado considerar una perspectiva de análisis centrada en la comunidad local. En este sentido, se llevaron a cabo:
1) Entrevistas semi-estructuradas a residentes actuales de la localidad, que funcionaron como informantes clave para conocer el devenir espacio-temporal del pueblo rural. Los interrogantes se orientaron a obtener información relativa a aquellos lugares que los propios habitantes consideran relevantes desde el punto de vista histórico-cultural y que presentan un simbolismo y significado particular. Se indagó acerca de las prácticas, usos sociales, características y dinámicas de estos espacios a lo largo del tiempo. Los entrevistados fueron seleccionados de acuerdo a los roles de relevancia que han cumplido en la localidad. En el primer caso, la ex directora (actualmente jubilada) de la escuela de educación primaria de Sundblad, quien además de impartir enseñanza a los alumnos del pueblo y los campos aledaños, fue promotora de distintos proyectos comunitarios; y en segundo lugar, a quien fuera panadero del único almacén de ramos generales que existe en la actualidad.

2) Se realizaron cuestionarios con preguntas de respuestas cerradas y abiertas (Tabla 1 ), que al igual que las entrevistas, tuvieron como objetivo conocer las vivencias y experiencias en torno a determinados lugares de valor histórico-cultural. Cabe aclarar que los sitios indagados a través de este instrumento de recolección de datos, fueron determinados a partir de los resultados de las entrevistas, siendo definidos por los mismos pobladores.

FIGURA 2

ESQUEMA METODOLÓGICO

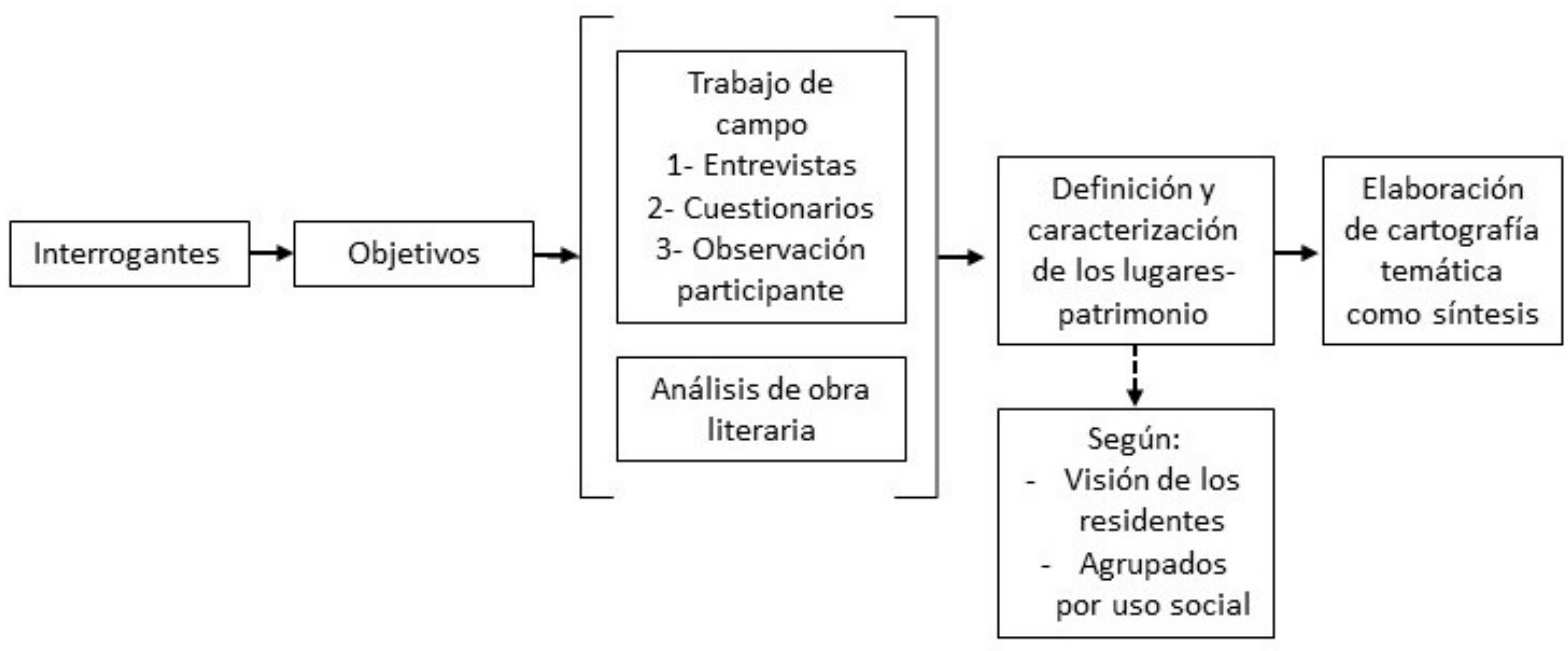

Fuente: Elaboración propia (2020). 
El muestreo fue de carácter no probabilístico o dirigido, aplicado tanto a actuales como a ex residentes de la localidad. Se decidió trabajar con estas dos categorías a fin de poder obtener la mayor cantidad de información posible, dado que gran parte de las personas que han migrado hoy en día son adultos mayores, por lo que pudieron aportar información relevante de la evolución del poblado. Asimismo, la mayoría de estos últimos, guarda vínculos familiares o laborales con el lugar, por lo que lo visitan de forma frecuente. Se obtuvieron respuestas de un total de 43 unidades de análisis (individuos).

3) Por último, se destaca como técnica a la observación participante en el terreno, a través de la intervención del autor de este artículo en dife- rentes actividades particulares de la comunidad, vinculadas a los procesos de puesta en valor del patrimonio local, como en diferentes proyectos culturales y la redacción de instrumentos legales de preservación patrimonial, algunos de ellos por iniciativa propia y otros a partir de un trabajo articulado con la institución de educación primaria de la localidad.

El trabajo de campo fue complementado con el análisis de una obra literaria que aborda el territorio bajo estudio. Ésta constituyó otra de las técnicas utilizadas para indagar acerca de la configuración de los lugares-patrimonio. En este caso, se analizó el libro de Elena Auguet ${ }^{3}$, quien en nupcias con un ferroviario vivió en la estación de tren de Sundblad durante un tiempo, inspirándola para escribir en el año 1996 la

TABLA 1

MODELO DE CUESTIONARIO APLICADO

Cuestionario: definiendo los lugares-patrimonio de Sundblad

Objetivo general: analizar la configuración de los lugares-patrimonio en Sundblad según la mirada de los actuales residentes y ex-habitantes de la localidad.

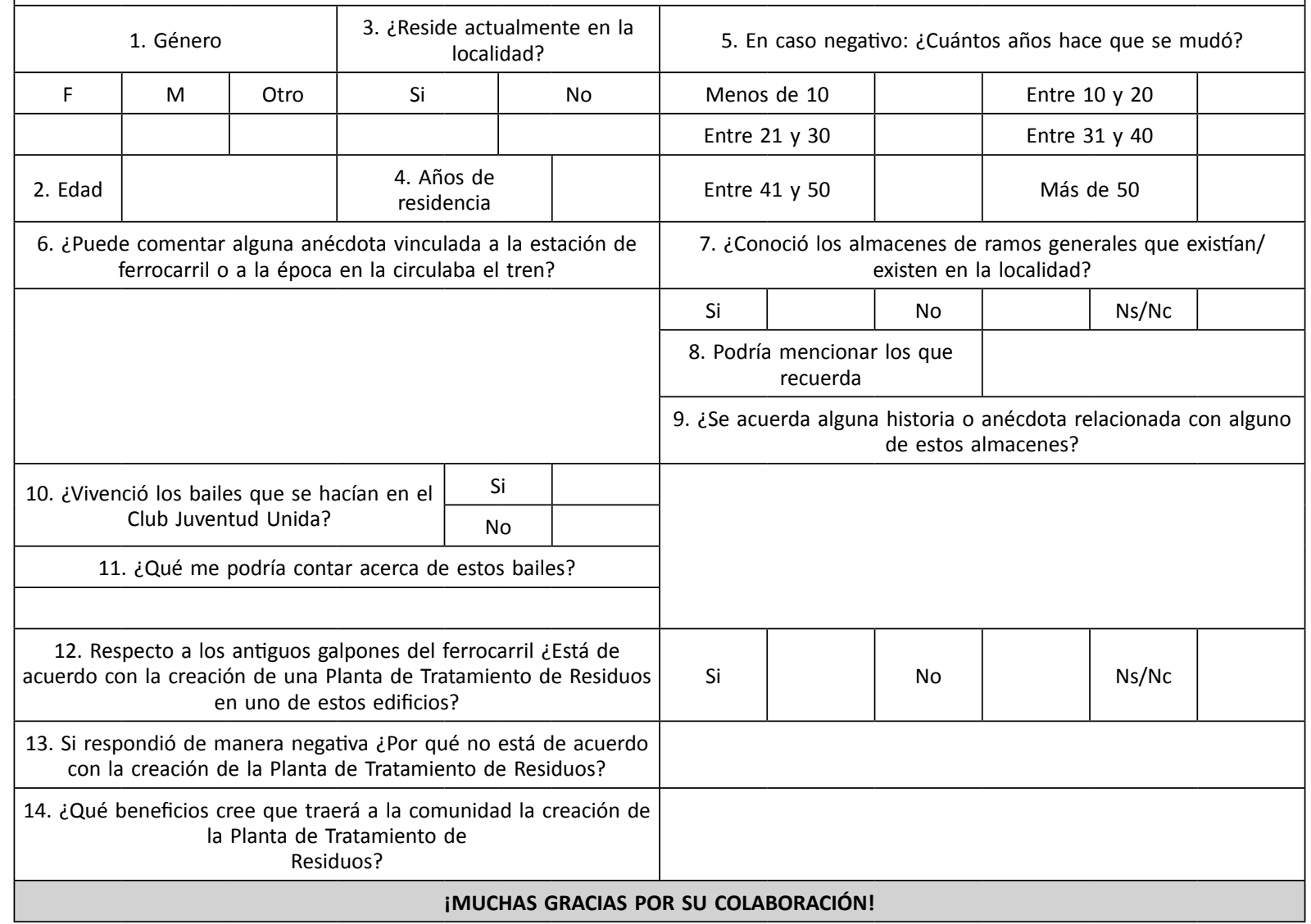

Fuente: Elaboración propia (2019). 
obra "Tiempo de Trenes". Este documento, que narra hechos verídicos, constituye un ejemplo relevante para la presente investigación, debido a la temática que aborda, por la diversidad de personajes y sitios que describe de manera pormenorizada en sus cuentos y por las distintas representaciones sociales que exhibe, construidas en torno al desarrollo del ferrocarril y la vida cotidiana en una típica localidad rural de la llanura pampeana argentina, durante las décadas de 1960 y $1970^{4}$.

A partir de los datos obtenidos, sobre la base de las técnicas aplicadas, se procedió a la identificación y caracterización de los lugares-patrimonio según la definición de los residentes, considerando además que las variables del contexto que operan en otras escalas geográficas, diferentes a la local, también condicionan de manera directa e indirecta su funcionalidad, estado de conservación y valoración social. Para el análisis de los mismos, no se consideraron de manera desagregada los resultados según la tipología de la técnica empleada, sino que se propuso un análisis integral a partir de una catalogación según el uso social de los lugares-patrimonio en: comercial y productivo, recreativo y asociados a la prestación de servicios. Asimismo, entre éstos se destacaron los que hemos denominado lugares-patrimonio en tensión, dada por las relaciones de poder entre distintos actores intervinientes. Por último, como síntesis del estudio realizado, se elaboró una cartografía temáti$\mathrm{ca}$, plasmando los diferentes componentes mencionados por los propios habitantes y aportando a la categorización establecida anteriormente, a partir de los cambios y continuidades en la funcionalidad de dichos bienes históricos.

\section{SUNDBLAD: CARACTERÍSTICAS SOCIOECONÓMICAS Y PROCESOS CONDICIONANTES DE LA CONFIGURACIÓN DE LOS LUGARES-PATRIMONIO}

Sundblad fundado el mismo día que la estación de tren homónima, el 19 de diciembre de 1911, se emplaza en la llanura pampeana argentina, específicamente en el noroeste de la provincia de Buenos Aires, en el distrito de Rivadavia (Fig. 3). El pueblo, que se estructura de manera paralela a las antiguas vías del Ferrocarril D. F. Sarmiento, se configura por 8 cuadrículas. Como toda localidad de características rurales, las manzanas no presentan una alta densidad ocupacional, sino que existen parcelas vacías que forman parte de terrenos fiscales.
Respecto a las actividades productivas, al igual que gran parte de los pueblos bonaerenses, la base económica la constituye la práctica agrícola-ganadera. Asimismo, se destacan algunos apicultores que se han instalado en la localidad hace más de treinta años.

En materia demográfica, según el último censo, el número de residentes asciende a 63 (INDEC, 2010). En relación con el del año 2001 se observa una disminución del 34\%, respecto de los 96 habitantes de ese momento. Dicho valor supera ampliamente a la media de decrecimiento de los pueblos de menos de 500 habitantes del total del país, que para el periodo 2001-2010 fue de 8,8\% (INDEC, 2001, 2010). Esto se enmarca en un contexto poco alentador del espacio rural que se origina a mediados del siglo $X X$, en contrapartida del despegue de los centros urbanos, que comienzan a crecer en número y tamaño. En el año 1941, Sundblad llegó a albergar hasta 450 residentes (Barios Barón, 2004). Este decrecimiento de los pequeños pueblos rurales de Argentina, al igual que la disminución de la población que se asienta de manera dispersa en el campo, se da de manera antagónica al crecimiento de los pueblos de mayor jerarquía en términos demográficos. Aquellas aglomeraciones rurales que albergan entre 500 y 1.000 residentes, aumentaron en número de habitantes permanentes un poco más del $4 \%$ entre los últimos dos censos (2001 y 2010), mientras que aquellas que tienen entre 1.000 y 2.000 lo hicieron a razón de casi el 5,5\% (Sili, 2019). Esto se relaciona con la migración que se produce desde el campo o las localidades de menor jerarquía a estos pueblos rurales, en busca de mayor acceso a servicios (de salud, culturales, recreativos, comerciales); la migración desde las grandes ciudades, por cuestiones de seguridad y tranquilidad; y por condiciones favorables de acceso a empleo y vivienda, en este último caso, a un menor costo o con mayores facilidades que las que se dan en el espacio urbano (Sili, 2019).

Con relación a las causas del despoblamiento del campo, los parajes y los pequeños pueblos rurales, condicionantes de la configuración y realidad actual de los lugares-patrimonio en la escala local, se destaca en primer lugar el proceso de crisis demográfica en el que se enmarca el territorio rural hoy en día, traccionado por el éxodo poblacional producido en las localidades de menos de 500 residentes y aquella que se asienta de manera dispersa. Esta crisis tiene su base en los años '30 con el desarrollo industrial, que conllevó a la sustitución de importaciones, y que se consolidó a partir de los ‘90 con la implementación 
FIGURA 3

LOCALIZACIÓN DE SUNDBLAD EN LA PROVINCIA DE BUENOS AIRES (REP. ARGENTINA)

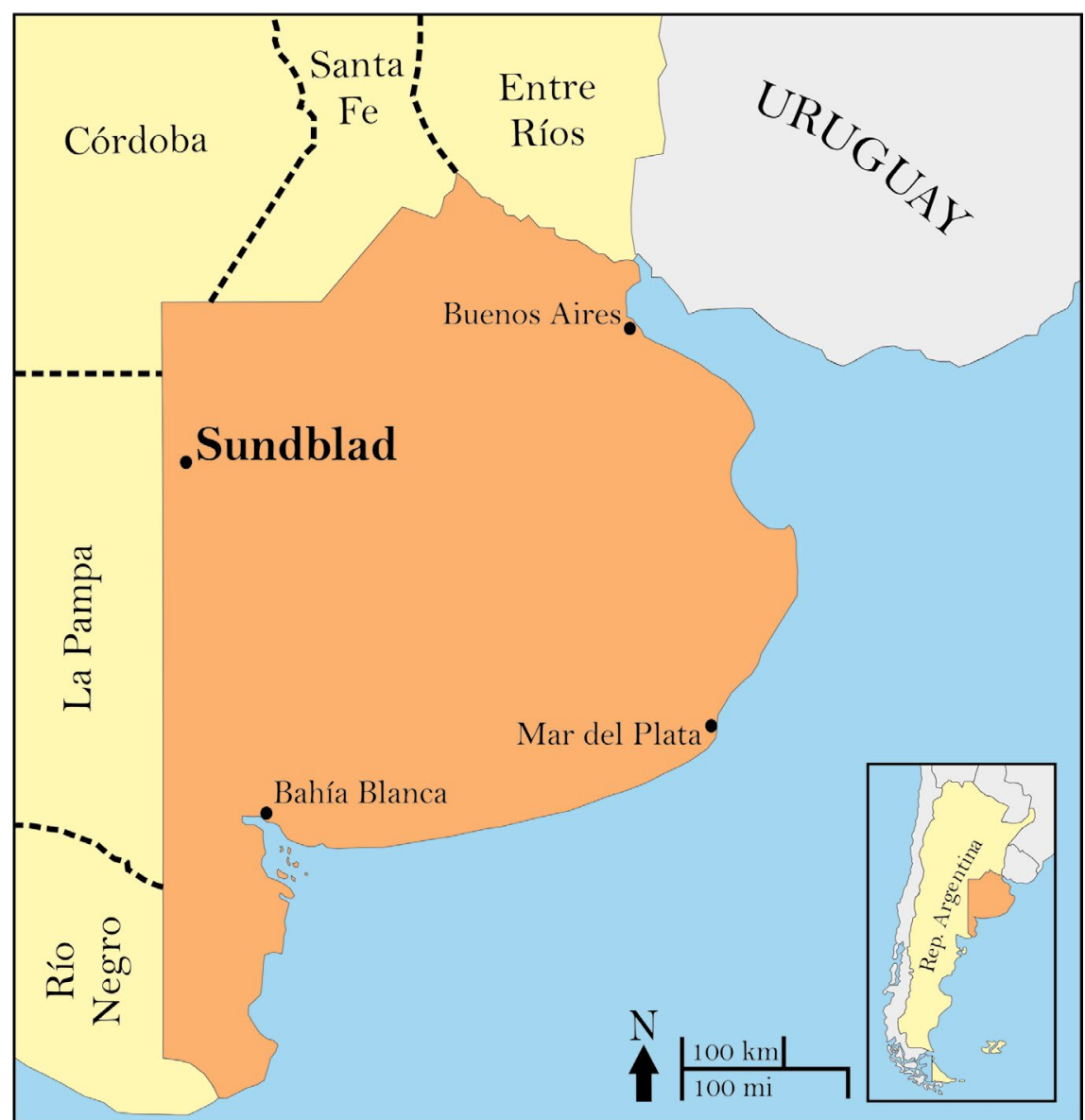

Fuente: Elaboración propia (2020)

de políticas de corte neoliberal (Sili, 2005, 2016; Sili, Guibert y Bustos Cara, 2015; Tedesco y Picardi, 2003). Esto condujo al cierre de ramales ferroviarios y al estancamiento de algunos pequeños pueblos y parajes, contribuyendo al abandono de equipamiento, infraestructura y construcciones vinculantes, conjuntamente con la pérdida de ciertas prácticas y representaciones sociales inherentes a una época de progreso nacional. A pesar de que la actividad férrea configuraba un sistema generador de un dinamismo socioterritorial relevante, Sánchez (2015) expresa que el cese del tren no estructura una causa genérica del despoblamiento de las pequeñas localidades, salvo en algunos casos específicos. El autor expresa al respecto:

... de manera general no es el tren el responsable del despoblamiento de las pequeñas localidades argentinas más allá de que ello haya sido cierto en algunos pocos casos. Sostener la idea generalizada de que declive fe- rroviario y despoblamiento es una ley de comportamiento no se basa en ninguna demostración empírica como si lo fue la relación entre despoblamiento rural y de pequeños pueblos y cambio tecnológico, de propiedad y organizacional en el agro (Sánchez, 2015, p. 53).

Otra de las variables del despoblamiento rural ha sido el proceso de modernización agrícola, que conllevó a la reducción de personal empleado de manera permanente en las tareas del campo, y a la migración de la población rural hacia las ciudades o pueblos de mayor tamaño, en busca de mejores oportunidades y condiciones de vida (Bertoncello, 1995; Sili, 2019).

Por último, se pueden mencionar como otro de los condicionantes del éxodo poblacional y, por lo tanto, del abandono de lugares hoy considerados de relevancia histórica, a los devenires climáticos poco favorables (periodos alternados de sequías e inundaciones) que se han dado en la región en la que se 
encuentra inmersa Sundblad, y que contribuyeron a que parte de los habitantes dejaran su residencia habitual. En el caso analizado se pueden destacar las inundaciones sufridas en los años 1984 y 2001, causadas por el desborde del Río V, emplazado en inmediaciones de la localidad.

Sin pretender un análisis pormenorizado de aquellos procesos determinantes de la disminución de la población rural, que se reflejan de manera clara en el caso analizado, el objetivo aquí es dar cuenta que estas dinámicas socioterritoriales que son generadas por factores del contexto, influyen en la configuración de los lugares-patrimonio, determinando cambios de funcionalidad o uso de ciertas formas del espacio geográfico, transiciones en los flujos de personas, obsolescencia y abandono de ciertos sitios, todo ello también traducido en los cambios en las representaciones, significaciones y valoraciones sociales de los lugares, dando cuenta que los mismos no funcionan como espacios refugio (aislados del contexto y cerrados en sí mismos), sino como construcciones permeables y en continua tensión.

Como se mencionara en la introducción, la selección de Sundblad como área de estudio se da a partir de la observación de dos procesos que conviven hoy en día en el espacio rural, por un lado la pérdida de residentes permanentes en estas pequeñas localidades del interior del país, que se traducen en el debilitamiento del capital histórico-cultural y, por el otro, un proceso de "resurgimiento rural" (Castro, 2018), que si bien para el caso indagado no se produce en términos de crecimiento demográfico, sí se visualiza a partir de estrategias incipientes de (re) valorización patrimonial por parte de actores locales. Asimismo, se pretende que la metodología aquí empleada constituya una herramienta susceptible de aplicación a otros contextos con características similares, dado que las dinámicas socioterritoriales que se dan en la localidad, resultan compartidas por distintos pueblos rurales de la región.

\section{La construcción de los lugares-patrimonio según la mirada de los habitantes}

Los habitantes de una determinada localidad configuran los actores sociales de mayor relevancia, dado que construyen su biografía espacio-temporal de manera cotidiana en la escala local. Cumplen un rol fundamental en los procesos de configuración de los lugares, debido que funcionan como inductores de valor social. Como se mencionara, estos lugares son puntos de tensión en los que se articulan diferentes intereses, según los agentes, procesos y objetivos perseguidos por cada uno de ellos, inclusive aquellos intervinientes en la escala extra local.

A partir de la visión de los residentes actuales y ex habitantes de Sundblad, se ha establecido una categorización de aquellos lugares del patrimonio cultural, que según sus representaciones y experiencias, configuran nodos de relevancia histórica y que, por lo tanto, son apropiados e internalizados en el espacio vivido de los individuos. Para organizar y ordenar el análisis, sobre la base de los diferentes lugares-patrimonio destacados por los sujetos durante la realización del trabajo de campo, se estableció una categorización en relación a la funcionalidad que cumplen o desarrollaban estos espacios cargados de valor. Es así que se destacan: 1) lugares-patrimonio vinculados a un uso comercial y productivo; 2) lugares-patrimonio relacionados con un uso recreativo y, por último, 3) los lugares-patrimonio asociados a la prestación de servicios. Como se estableciera, si bien en estos apartados se focaliza en la mirada de los habitantes de Sundblad como constructores de los lugares-patrimonio, la situación actual de éstos, tanto en términos materiales como en el ámbito de las representaciones, se ve condicionada por las variables del contexto político, económico y social y por aquellas relaciones que se dan con otros actores sociales en escalas geográficas diferentes a la local. Esto conduce también a analizar, más allá de las categorías propuestas, a aquellos lugares en los que se visualizan tensiones o conflictos, a partir de estas vinculaciones.

En el análisis, que se presenta de manera integral, se articula la información procedente de las entrevistas semi-estructuradas, de los cuestionarios y de la descripción de los lugares que realiza Elena Auguet, antigua residente y autora en la obra literaria "Tiempo de Trenes". Como se estableciera, no es el objetivo del trabajo presentar de forma disgregada los resultados de las técnicas empleadas, si no aportar a partir de una mirada integradora.

Con relación a las características de los individuos que formaron parte de la muestra dirigida para la realización de los cuestionarios, se destaca en mayor proporción el género femenino (Fig. 4). Respecto a la edad, predomina el segmento de adultos (entre 19 y 59 años), seguido por los adultos mayores (a partir de los 60 años de edad). Un poco más de la mitad $(51,2 \%)$ configuran ex residentes de la localidad, mientras que el porcentaje restante $(48,8 \%)$ se co- 
rresponde con aquellos que actualmente viven en Sundblad. El 33,3\% de estos últimos, afirmó residir en la localidad desde que nació, mientras que aquellos que no lo hacen actualmente, en su mayoría han decidido migrar hace más de 30 años.

\section{Lugares-patrimonio vinculados a un uso comercial y productivo}

Entre los lugares vinculados a un uso comercial y productivo, que resurgen entre las historias de vida de los residentes, se puede mencionar en primer lugar a la estación de tren (Fig. 5). Ésta se presenta como un nodo articulador entre el espacio local y el extra local, como un sitio dinámico que excede la función económica y de transporte para posicionarse como referente de las representaciones y significaciones sociales. La estación y su andén definen lugares de intercambio no sólo productivo, sino también de relevancia cultural y simbólica. El andén configuraba un espacio de recreación, donde el arribo del tren erigía un atractivo en sí mismo y un punto de reunión, acotado en el tiempo, y definido por la llegada y partida de la locomotora y los vagones. En una de las entrevistas realizadas a uno de los actuales residentes, C. P. de 57 años de edad ${ }^{5}$, nacido y criado en Sundblad, expresa:

Desde cuando yo tengo conocimiento, el ferrocarril ya era muy importante en Sundblad... Corría el tren de pa- sajeros que pasaba una o dos veces a la semana; y venían los trenes cargueros, que traían vagones vacíos para cargar cereal en bolsas de arpillera en el galpón... Había camiones locales que se dedicaban al flete del campo al ferrocarril, donde la bolsa se estibaba y guardaba en los galpones de acopio y después se cargaban al tren... El que venía a trabajar en la cuadrilla y era de afuera, paraba en el pueblo...

Era todo un acontecimiento la llegada del tren, porque no había otra cosa en el pueblo. Entonces íbamos todos, para ver quién viajaba, quién se bajaba. Era ir al andén, esperarlo, ver un poco el movimiento y después venirnos (C. P., 2019).

Como en gran parte de los pueblos rurales bonaerenses y de la Argentina, con el debilitamiento y crisis del sistema ferroviario, consolidado en la década del '90 con la privatización de servicios del Estado, los complejos férreos entran en una etapa de obsolescencia y abandono, que se traduce en espacios en retroceso producto de la pérdida de su funcionalidad. Algunos de éstos, con el paso del tiempo fueron beneficiados por determinadas estrategias de puesta en valor, llevadas a cabo por agrupaciones de la sociedad civil o por las administraciones públicas, que buscaron reconvertir estos sitios destinándolos a un uso diferencial al original, ya sea como espacios de la memoria a través de museos, como centros culturales o sitios de uso comunitario. Por otro lado, en la mayoría de los casos, gran número de estos inmuebles se encuentran inutilizados y en estado de deterioro. En la

FIGURA 4

CARACTERÍSTICAS DE LA MUESTRA ANALIZADA (CUESTIONARIOS)
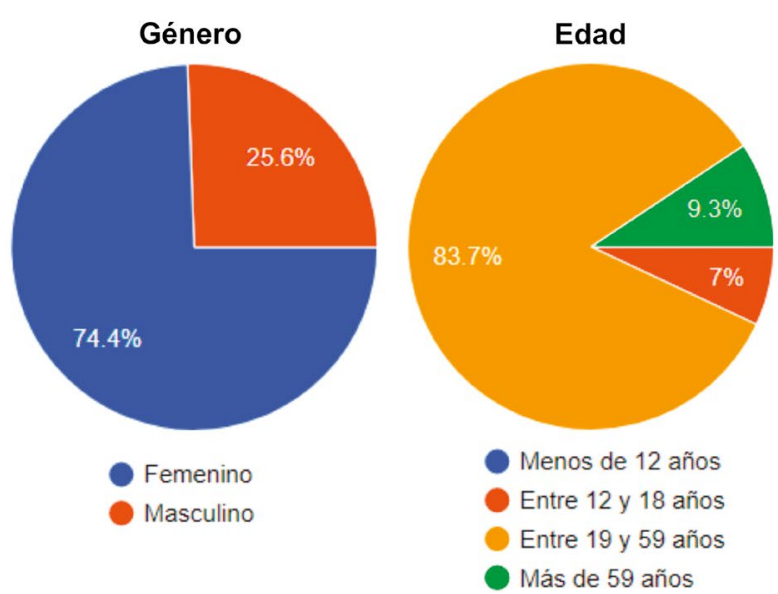

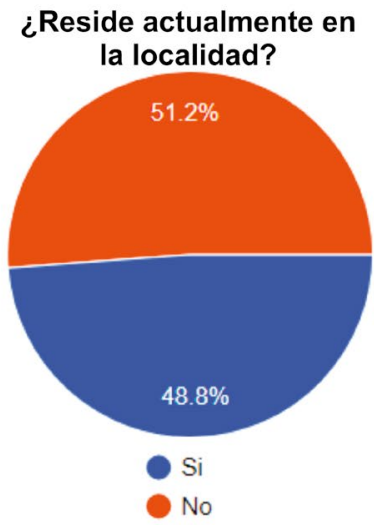

¿Cuánto tiempo hace que emigró de Sundblad?

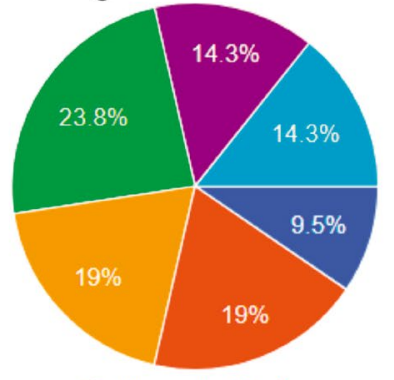

Menos de 10 años Entre 10 y 20 años Entre 21 y 30 años Entre 31 y 40 años Entre 41 y 50 años Más de 50 años

Fuente: Elaboración propia (2019). 

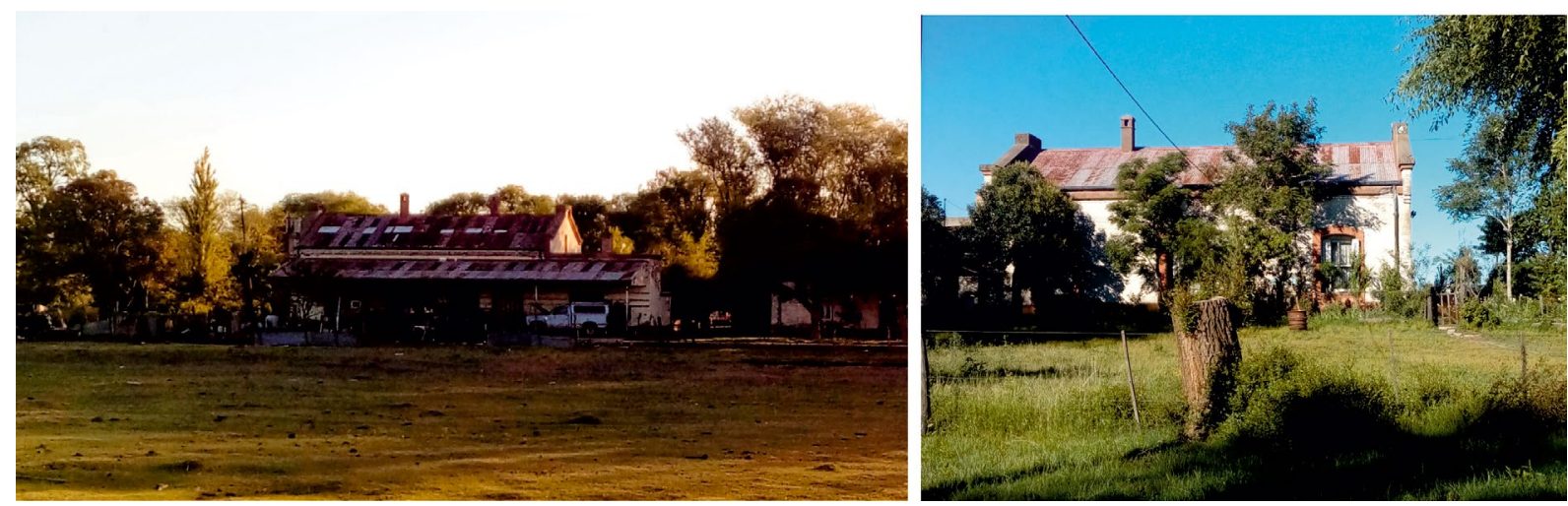

Fuente: Fotografías del autor (2019).

localidad de Sundblad, tanto la estación de tren como las antiguas viviendas del guardahilos y el cambista, albergan un uso residencial, lo que en términos generales posibilita que se sigan manteniendo. Asimismo, en uno de los antiguos galpones de acopio, se ha dado un proceso de refuncionalización por parte del municipio, creando una planta de tratamiento de residuos. Esta propuesta se origina en el año 2014, con la sanción de la Ordenanza Municipal № 3.583, que legitima como "Patrimonio Histórico y Urbano Municipal" a la totalidad del complejo del Ferrocarril Oeste.

Para los habitantes más antiguos este sector del poblado configura un verdadero lugar patrimonial, donde su inmaterialidad se refleja en las representaciones y significaciones asociadas al mismo. La minuciosa descripción que realiza Elena Auguet en uno de sus relatos, permite generar un imaginario diáfano acerca del paisaje de aquella época:

... El ruido del tren enganchando los vagones se acerca al galpón, el sonido metálico de las chapas, el sordo golpear de las bolsas repletas de cereal, el chirriar de las chatas cargadas, los gritos de los bolseros, de los cambistas, los guardas, todo eso se le une en la tarea dura, fatigosa donde los jornaleros sudorosos trabajan por un par de pesos que llevarán a sus hogares, algunos otros... directamente al mostrador del boliche a tomarse la vida en una copa (Auguet, 1996, p. 42).

La antigua residente de la estación describe uno de los escenarios cotidianos no sólo de Sundblad si no de los pueblos rurales en general. Las dinámicas socio-espaciales que generaba el ferrocarril se traducían en un paisaje significativo, constituido por prácticas consideradas insignificantes por cotidianas, que hoy en día han desaparecido al extinguirse la actividad férrea.

Como parte de la configuración de estos lugarespatrimonio, se destacan un cúmulo de anécdotas e historias de vida asociadas a la estación y al tren en la localidad, que hoy en día se siguen contando y trasmitiendo de generación en generación. En la Tabla 2 se resaltan algunas de las expresiones de los residentes, obtenidas a partir del trabajo de campo realizado. Entre éstas aparecen los recuerdos nostálgicos que rememoran las prácticas sociales en torno al ferrocarril, coincidiendo todos los residentes en la dinámica que otorgaba al pueblo el arribo y partida del tren.

Estas historias de vida, dan cuenta de la representatividad que ha alcanzado el desarrollo del ferrocarril en estos pueblos rurales, inclusive induciendo procesos de reafirmación de estas identidades. En el caso de Sundblad, la fecha de fundación se estableció por iniciativa de un ex residente de la localidad, que por motivo propio, desinteresadamente y sin representar a ninguna organización, impulsó tal legitimación por Ordenanza Municipal № 4.220/19, reconociendo el día de arribo de primer tren cómo hito de conmemoración del aniversario del pueblo. Esta propuesta fue apoyada por la comunidad en su conjunto.

Otro de los lugares significativos para los residentes eran los almacenes de ramos generales. Éstos estructuran sitios con un gran valor simbólico a lo largo de la obra literaria de Auguet (1996), dado que se reiteran en numerosas oportunidades. Asimismo, denotaron importancia para los ex residentes y para los actuales. Al igual que la estación de tren, éstos excedían la función de abastecimiento de productos diversos, para erigirse como lugares de encuentro y 
TABLA 2

ANÉCDOTAS DE LOS RESIDENTES EN TORNO AL FERROCARRIL

"Según relatos escuchados de quienes vivieron toda la vida aquí, era todo un acontecimiento a la hora de la llegada del tren. Los pobladores se reunían para esperarlo, socializaban, los niños jugaban en el andén, o sea un punto de encuentro."

"Viví en la estación. Recuerdo con nostalgia el terrenito anexo, con un árbol altísimo."

"Cuando era chico, el tren hacía años que había dejado de pasar, aun así mí viejo contaba siempre sus días de trabajo hombreando bolsas en los galpones."

"Recuerdo cuando se arrojó al tren un empleado ferroviario, entre Sundblad y el paso nivel de San Jorge."

"Recuerdo cuando iba a la estación a ver pasar el tren y a jugar."

“El tren traía desde las vacunas para el ganado de la Cooperativa de Roosevelt, hasta el paquete de revistas que se vendían en el pueblo."

"Me acuerdo que vivía en la estación el señor Gallo con su familia."

"Mis recuerdos son la llegada del tren a la tardecita, se veía la luz de la máquina desde lejos. Nosotros esperábamos en la estación y recorríamos los vagones."

"Muchas anécdotas recuerdo, entre ellas: los bailes de los domingos en el andén de la estación."

Fuente: Elaboración propia (2019).

recreación. Configuraban punto de reunión e intercambio a la hora de "hacer los mandados".

Por otro lado, también se destacaban otros comercios, como confiterías y un hotel. En palabras de uno de los entrevistados, se destaca:

Nosotros teníamos la panadería del pueblo... También en la calle principal o de entrada, como le decimos nosotros, estaba el almacén de ramos generales de Ruben Mateucci. Tenía de todo: ferretería, alimentos, combustible... y el almacén de Carlos Sobrero, que estaba en la otra cuadra cercana, que también era de ramos generales, no tan completo como el anterior; hasta supo vender nafta en los surtidores a manija... También hubo un hotel, el Hotel de Fraga, pero desde que tengo uso de razón, éste ya no existía. Una parte se había desarmado y había pasado a ser el club. $Y$ en la otra esquina, había una confitería en la que se hacían bailes. Era un bodegón que iban a tomar copas, a jugar a las cartas. Luego con el tiempo se convirtió en una barraca (C. P., 2019).

Las carnicerías también fueron importantes en la localidad. Según las palabras de otro de los residentes actuales, que vive en Sundblad desde el año 1984, se destaca:
En aquella época [en relación a la década del ' 80 y '90] había una carnicería del Sr. Galván, a media cuadra de mi casa, a la que iba a comprar. También estaba la Subdelegación Municipal abierta, que no era un comercio, pero era un lugar público donde se podía ir a hablar por teléfono... Cuando cerró la carnicería de Galván, abrió otra de Roberto Churruca, a tres cuadras de mi casa... También alcancé a ir alguna vez al almacén de ramos generales de Sobrero. Era un lugar antiguo, con unos mostradores y piso de madera, tenía estanterías altas (G. M., 2019).

Actualmente, solamente existe el Almacén de Ramos Generales de Heberto Pinassi, sobre la calle de ingreso al pueblo rural. Si bien el comercio comenzó sus actividades como panadería, hoy en día comercializa una gama diversa de productos. Debido a las carentes ventas de pan, vinculadas por el reducido personal con el que cuentan las estancias de la zona y por el número acotado de pobladores, desde hace un tiempo se comenzó a traer de manera diaria este alimento desde la localidad de Fortín Olavarría, ubicada a 15 kilómetros.

A partir de las historias expresadas por los residentes y sobre la base de lo destacado por Auguet, otro de los lugares comerciales relevantes era la Fábrica de Quesos. Ésta se creó en 1948 por iniciativa de la Cooperativa de Tamberos de la localidad. En ella se elaboraban quesos de diferentes variedades: Chubut, Pategrás, Sardo, Brinz, entre otros. La logística de los mismos se realizaba a través del tren y se vendía a diferentes puntos de Mendoza, La Pampa y la zona. Desde su creación, y hasta su cierre, diferentes personajes reconocidos a nivel local, se desempeñaron como queseros. En 1965, debido a la falta de tambos que abasteciera a la empresa, se produce el cierre definitivo (Pinassi, 2012).

Entre la diversidad de locales comerciales, según palabras de los entrevistados, también se destacaba una mercería, que funcionó hasta 1975 . La variedad de establecimientos alcanza también una herrería, del señor Ignacio Fritz, sobre el acceso a Sundblad; y una sodería, que funcionó en sus inicios en una de las dependencias del Club Juventud Unida, trasladándose luego al inmueble lindero.

\section{Lugares-patrimonio vinculados a un uso recreativo}

En el ámbito de la recreación y el esparcimiento, como se destacara, los almacenes de ramos generales más allá de estructurar lugares con una funcionalidad comercial, constituían espacios de sociabilización destinados 
al encuentro de los vecinos, principalmente por la tardenoche. Asimismo, en la localidad funcionaron por un tiempo algunas confiterías, en las que también se prestaba el servicio de comida. Uno de los residentes entrevistados resalta en relación a estos sitios:

Uno era el almacén de ramos generales de Ruben Mateucci e Ítalo Mateucci, su padre, que tenían en el mismo lugar un despacho de copas en el que la gente se juntaba en las tardecitas, que venía a hacer las compras desde el campo (Fig. 6) ... y después de ahí se iban a la cancha de pelota paleta, frente al almacén de Sobrero, que había otra confitería, que era como un bodegón que daban de comer o para tomar algo... A su vez, tenía una o dos piezas por si alguno quería pasar la noche... En la cancha de pelota paleta se juntaba mucha gente a jugar por la cerveza o por algunos pesos, venían de otros pueblos: Roosevelt, Fortín Olavarría. Se cobraba un alquiler por tiempo (C. P., 2019).

Cabe destacar que este comercio desarrolló sus funciones hasta la década del '70, cuando sus propietarios se mudan a la ciudad de General Pico en La Pampa. A partir de allí, estas construcciones representativas de la arquitectura italianizante, de ladrillo visto, fueron ocupadas por familias de apicultores que se asentaron en la localidad. Actualmente, el lugar en el que funcionaba el almacén de ramos generales se lleva a cabo la extracción de miel, mientras que la cancha de pelota paleta es destinada al guardado de herramientas y elementos propios de esta misma actividad. En ambos casos, el deterioro material, causado por la falta de mantenimiento y el paso del tiempo, se trasforma en una característica notoria de este tipo de inmuebles.
Otro de los lugares recreativos mencionados como parte del espacio vivido de los residentes es el Club Juventud Unida. Éste, creado en el año ‘41, funcionó de manera regular hasta mediados de la primera década del 2000. A partir de allí, solamente abre sus puertas para eventos puntuales. Asociados a este componente patrimonial surgen como parte de las representaciones sociales, los bailes característicos de Sundblad, que eran reconocidos en el contexto regional, según palabras de los entrevistados.

El club funcionaba, pero era solamente para que vayan los hombres, porque no había cosas o actividades que las mujeres pudiéramos hacer. Los hombres jugaban a las cartas, a las bochas, y para las mujeres no había nada; salvo que nos encontráramos en algún lugar para tomar mate o charlar, o si no en algún evento que por ahí organizaba la escuela, algún baile, algún campeonato de chinchón, y no mucho más...

Primeramente, los bailes eran en el club. Posteriormente se ve la posibilidad de que se juntaba mucha gente y que se podía hacer cena con baile, entonces decidimos hacerlos por un tiempo en los galpones del ferrocarril. Se contrataba una orquesta, se armaba un escenario, una cantina, los mismos baños los hacíamos con chapa y se reunían entre 400 y 500 personas de toda la zona... Esto se hizo 4 o 5 años y se dejaron de hacer, porque había que tener mucho compromiso y trabajar mucho, de manera desinteresada (G. M., 2019).

Un dato interesante que cuenta otro de los residentes con relación a la realización de los primeros eventos en los galpones de acopio del ferrocarril, es la convivencia de los dos tipos de uso, por un lado,

FIGURA 6

INMUEBLE PERTENECIENTE AL ANTIGUO ALMACÉN DE RAMOS GENERALES DE MATEUCCI (1932), ACTUAL DEPÓSITO DE APICULTORES

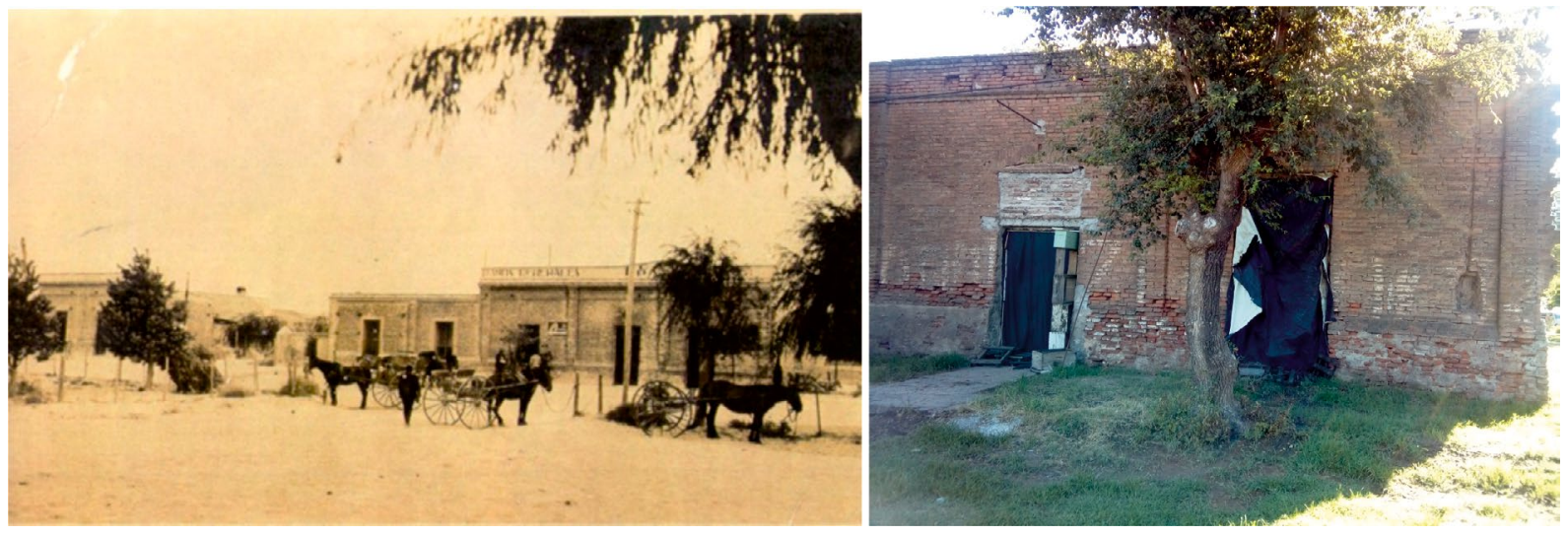

Fuente: Fotografías del autor (2019). 
el de esparcimiento y, por el otro, aquel ligado a la actividad productiva.

El club se abría cuando se hacían los bailes por el aniversario o por otro motivo que se quisieran organizar. Cuando éstos eran más grandes, se hacían en el galpón del ferrocarril. Se dividía a la mitad el galpón con bolsas de arpillera, porque la otra parte tenía lienzos de lana acumulada para cargar en el tren (C. P., 2019).

Estos acontecimientos programados configuraban puntos de inflexión en la rutina de los pobladores, dado que la comunidad en su conjunto trabajaba en pos de su organización. Desde el punto de vista de las representaciones sociales, los mismos forman parte de todas las historias de vida de los habitantes, tanto los actuales como aquellos que alguna vez vivieron en la localidad. Inclusive, hoy en día perduran algunas anécdotas, trasmitiéndose a las nuevas generaciones que no llegaron a vivenciar este tipo de prácticas sociales (Tabla 3). Al igual que sucede con los espacios productivos y comerciales, los entrevistados destacan el importante número de asistentes que recibían estos bailes, otorgando una dinámica totalmente diferencial, a la que estaban acostumbrados cotidianamente.

TABLA 3

ANÉCDOTAS DE LOS RESIDENTES VINCULADAS A LOS BAILES DE CAMPO

"Se hacían los bailes para la fecha aniversario del club, se contrataba una orquesta de la zona y se hacían muy lindos bailes, no fallaba ninguno, porque venía gente de pueblos vecinos y de las colonias lindantes, como la colonia $\mathrm{El}$ Triángulo y colonia El Balde. También se acostumbraba a pedir donaciones a la gente del pueblo que quisiera colaborar con tortas o bebidas, y en un intervalo del baile se hacía un remate de las mismas. También se preparaba una mesa servida con un lechón cocido, con botellas de bebidas y algún alimento más... y se sorteaba antes de concluir el baile."

"Todos los bailes eran un éxito, con mucha gente, porque aún todos los campos estaban habitados. Además concurrían de otras localidades."

"Bailes hermosos e inolvidables."

"Iba gente de toda la región."

"Yo era muy chico, pero recuerdo que llegaba muchísima gente de la zona."

"Eran muy lindos. Concurría mucha gente. Eran bailes que no 'fallaban'. Sobre todo el del aniversario del club, el 31/08, generalmente con la orquesta de Lito Rodríguez."

"Recuerdo los bailes con orquesta, alumbrados con los faroles Petromax..."

Fuente: elaboración propia (2019)
Estos acontecimientos programados fueron realizados hasta finales de 1990. Hoy en día, no se llevan a cabo actividades de tal magnitud. Solamente se organiza un almuerzo en el mes de septiembre, que se desarrolla en el Club Juventud Unida, como forma de recibimiento a una cabalgata de relevancia distrital.

A partir del relato de los habitantes, se infiere que en términos generales los lugares destinados a la recreación y el esparcimiento estaban orientados principalmente a los hombres, acotándose las propuestas dirigidas a las mujeres a algún evento particular. Actualmente, más allá de la cancha de fútbol que se encuentra en las inmediaciones de la escuela primaria local, no existe otro espacio que de manera regular y cotidiana permita satisfacer las necesidades culturales y recreativas de los residentes. Sin embargo, el único almacén de ramos generales que permanece abierto, sigue funcionando como un punto de encuentro para los trabajadores de los campos aledaños, que interrumpen su rutina y como parte de un "ritual sagrado" arriban al pueblo a proveerse de alimentos. Esta práctica es una de las pocas que se conservan aun, más allá de los cambios a través del tiempo. En uno de sus relatos, con cierta ironía Auguet destaca:

Los parroquianos van llegando de a uno, como desgranando esa vieja costumbre que les ayuda a descargar las tensiones cotidianas... Esa cotidianeidad tiene ya muchos años y nunca se preguntan el porqué de esa fidelidad a ese mísero boliche. Allí el café no es muy bueno, la cerveza nunca está bien fría y los maníes del vermouth tienen un nostálgico sabor a humedad. Es más fuerte que ellos mismos, sencillos hombres de pueblo, la costumbre de juntarse en el bar. Allí discuten sobre política, mujeres, fútbol, o el truco circula entre ellos... (Auguet, 1996, p. 69).

\section{Lugares-patrimonio relacionados a la prestación de servicios}

En esta última categoría propuesta, y según la mirada de los residentes, se destaca la Escuela Primaria № 12. Actualmente, ésta constituye la única institución en Sundblad encargada no sólo de la educación formal, sino también que es promotora de actividades y diversos proyectos en la escala local. La institución comenzó a funcionar en una vivienda precaria, habitada por la familia Méndez, luego en otra construcción sobre el ingreso a la localidad (en la que residiera la familia Martorel), también se desarrolló en el Club Juventud Unida, hasta que finalmente se traslada al 
edificio actual, en el extremo sur de la trama del poblado. Una de las vecinas entrevistadas resalta con relación a los lugares históricos:

A criterio personal, si tuviera que mencionar un lugar histórico, sería la escuela, pero también reconozco que el club, la estación de ferrocarril, los almacenes de ramos generales, la vieja confitería, la cancha de paleta, también son importantes. También hay otras casas emblemáticas donde funcionó en sus inicios la escuela. Todos estos tienen una historia riquísima, pero muchos la desconocen o no se despierta el interés por indagarlas, pero todos tienen su lado histórico (G. M., 2019).

A partir de los registros de archivo de la institución, la educación comienza a impartirse en Sundblad en los inicios de la segunda década del siglo XX, funcionando en viviendas de carácter modesto, hasta que en 1952 se construye el edificio actual.

Los habitantes también rememoran en el marco de aquellos lugares vinculados a la prestación de servicios, al destacamento policial, antiguamente erigido en inmediaciones de la escuela ${ }^{6}$. Luego de su función de comisaría, el inmueble fue ocupado por apicultores, adquiriendo un uso residencial, hasta que finalmente en la primera década del 2000, dado su inadecuado estado de conservación, culmina convirtiéndose en ruina. En relación a ello, uno de los pobladores expresa: "Otro de los lugares históricos importantes es la comisaría, cuando existía. Estaba muy bien preparada, con el mástil, en el que se ponía la bandera en los días patrios" (C. P., 2019). Si bien hoy en día no existen vestigios materiales del destacamento policial, el mismo forma parte de la memoria colectiva de los residentes. Es decir, constituye un patrimonio afectivo que excede el valor tangible o formal.

\section{Lugares-patrimonio en tensión}

Como se manifestara al comienzo de este trabajo, más allá de la concepción de lugar desarrollada en el ámbito de la geografía humanista y abordada hasta aquí con mayor detenimiento en el caso de estudio propuesto, existen otras posturas alternativas que establecen su proceso de configuración a partir de las relaciones de poder que se producen de manera interescalar. En Sundblad esta tensión entre intereses diversos, relacionados a la construcción de los lugares patrimoniales, se visualiza en torno al complejo ferroviario, dado que se han llevado a cabo una serie de iniciativas con el objetivo de poner en valor algu- nos de los compontes históricos que alberga. El foco de tensión se produce a partir de los procesos sociales que inducen este tipo de estrategias de patrimonialización y de los actores que entran en juego.

En este sentido, se identifican propuestas concretas llevadas a cabo por residentes de Sundblad, como la redacción del proyecto de ordenanza para legitimar como patrimonio histórico el legado ferroviario en su conjunto, o el proyecto recreativo-educativo impulsado por la escuela de educación primaria de la localidad. En este último caso, la institución educativa en conjunto con algunos habitantes, entre los años 2014 y 2015 redactaron y presentaron ante el gobierno municipal un proyecto denominado: "La recreación en el ámbito escolar, como alternativa de revitalización patrimonial en la localidad de Sundblad (provincia de Buenos Aires)", que tuvo como objetivo refuncionalizar uno de los antiguos galpones de acopio del ferrocarril como espacio deportivo y cultural. En virtud de ello y luego de su tratamiento, el municipio no da lugar a esta propuesta ciudadana participativa, decidiendo por iniciativa propia y sin ningún mecanismo de socialización o de intercambio comunitario, convertir al lugar histórico en una planta de tratamiento de residuos (Fig. 7). Se construye así un discurso autorizado en relación al impacto económico que podría impulsarse, a partir de la generación de empleo y del ingreso que se obtendría como resultado del procesamiento de la basura y de los productos finales que se comercializarían. A pesar de que esta iniciativa contó con el apoyo de casi el $62 \%$ de los encuestados que actualmente viven en la localidad (más de los dos tercios se encuentran representados por el género femenino, perteneciente al segmento entre los 19 y 59 años de edad), según los datos recabados durante el trabajo de campo en esta investigación, existe un porcentaje relevante de residentes, casi el $24 \%$, que considera que el desarrollo de esta nueva funcionalidad en el inmueble histórico, contribuirá a un deterioro ambiental en el pueblo rural (Tabla 3), mientras que un poco más del $14 \%$ no contestó al respecto.

En relación a aquellos que no residen hoy en día en Sundblad, se acrecentó a casi el $73 \%$ la concordancia con la propuesta del municipio (también preponderando el género femenino y el grupo poblacional de adultos), mientras que un poco más del $13 \%$ no estuvo de acuerdo, alcanzando el mismo valor que aquellos que no contestaron el interrogante. En este contexto, algunos de los ex habitantes manifestaron su disconformidad: 
FIGURA 7

ANTIGUO GALPÓN DE ACOPIO DEL FERROCARRIL OESTE, ACTUAL PLANTA DE TRATAMIENTO DE RESIDUOS

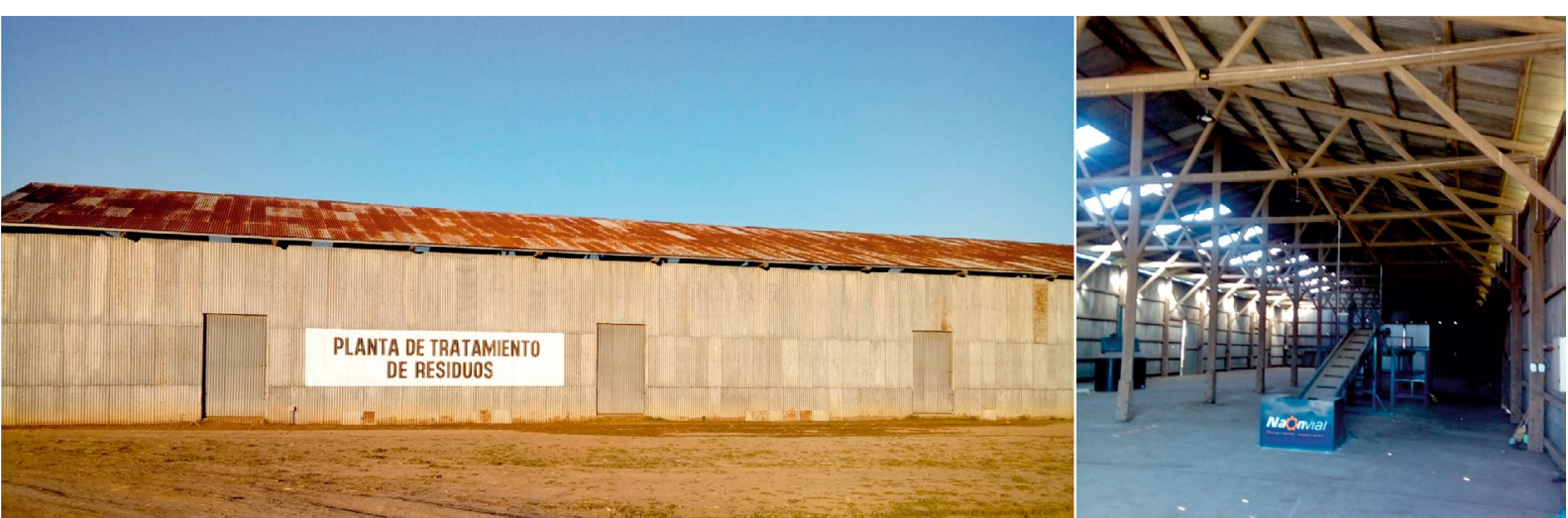

Fuente: Fotografías del autor (2019).

Una pregunta: ¿Está en condiciones el galpón para ser una planta de residuos? La verdad me da mucha pena ver en las condiciones que se encuentra ¿Tiene habilitación? Eso me gustaría ver si es así. La verdad que me siento muy triste, al ver que transformen a mi querido Sundblad en un basurero. Tiempos de política... Nadie hace ni dice nada, parece que todo está de diez (Publicado en la red social Facebook, 22-10-2019).

TABLA 4

OPINIÓN RESPECTO A LA REFUNCIONALIZACIÓN DEL ANTIGUO GALPÓN DE ACOPIO COMO PLANTA DE TRATAMIENTO DE RESIDUOS

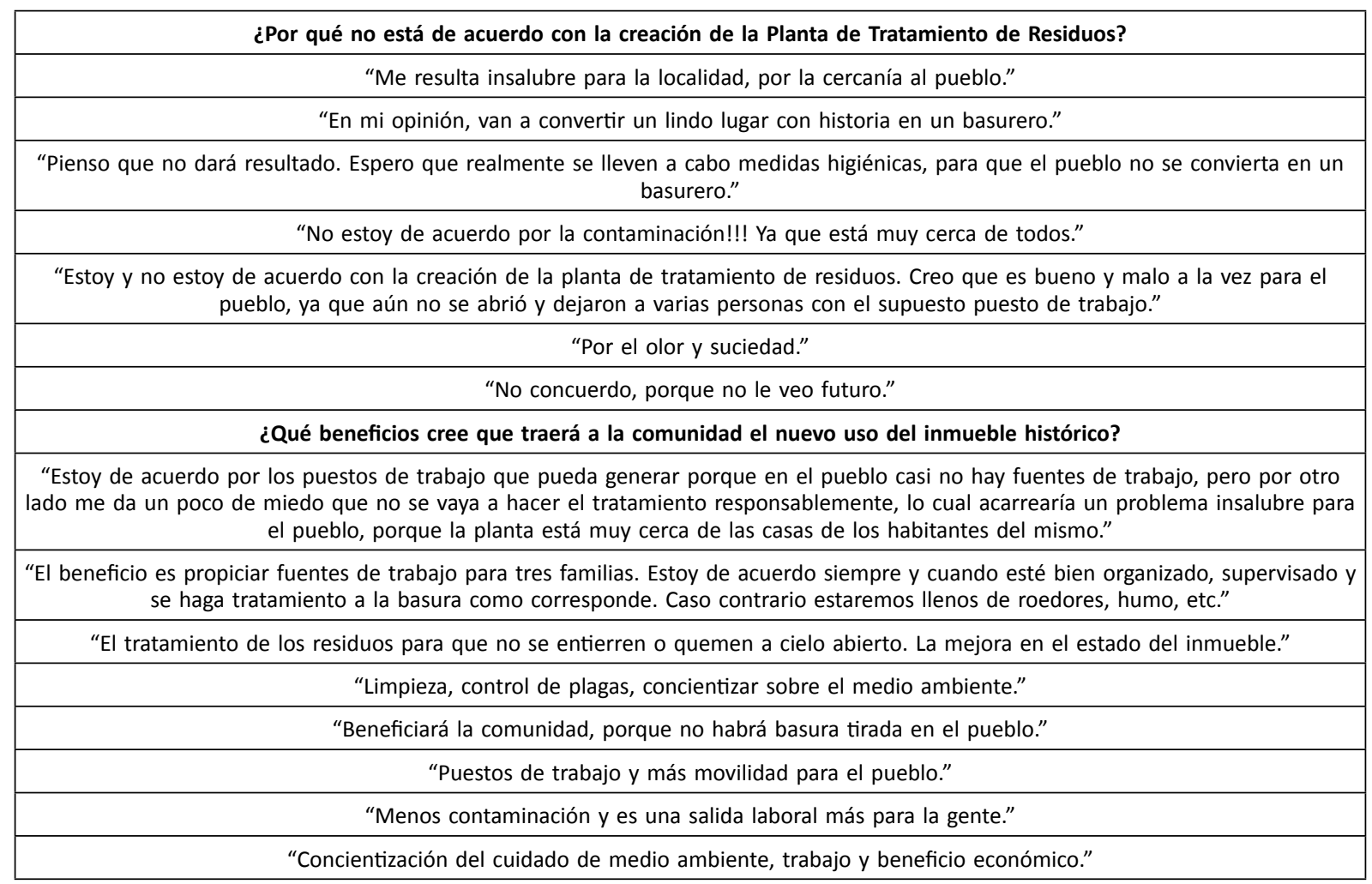

Fuente: elaboración propia (2019) 
Con relación a los individuos que apoyaron la propuesta de refuncionalización por parte del gobierno municipal, éstos adhirieron al discurso vinculado al empleo que se generará en la comunidad y a la contribución del cuidado del ambiente. Gran parte de las respuestas obtenidas en el terreno, se expresaron en ese sentido (Tabla 4).

A partir de este caso particular, pueden visualizarse los conflictos que se producen entre los diferentes actores involucrados: por un lado, los residentes que construyen su espacio vivido de manera cotidiana en la localidad; y por el otro, el Estado Municipal, que opera en la escala extra local, a través de representantes políticos que deciden el destino de los componentes patrimoniales. Si bien la iniciativa alcanzó el consenso de los pobladores, se resalta la hegemonía del poder político en la imposición del uso social asignado al inmueble, dado que la idea inicial de los ciudadanos se fundamentó en otra funcionalidad y con objetivos disímiles a la propuesta desarrollada.

En este sentido, los procesos de patrimonialización, de asignación de valor, son los promotores de las tensiones generadas en torno a estos lugares-patrimonio, dado que a partir su activación entran en juego las relaciones de poder e intereses de los agentes intervinientes. En definitiva, es el poder político en este caso, quien legitima o no estos mecanismos, quien acompaña en la valorización del componente histórico, y quien ejecuta las decisiones acerca del destino del mismo. Se generan así disputas entre un lugar con una valoración social notoria por parte de los residentes, que se traduce en sus representaciones y significaciones, y un uso social del sitio definido en otra escala, con agentes e intereses que no operan de manera cotidiana en el espacio local.

\section{A modo de síntesis: cartografiando los lugares-patrimonio}

A fin de sintetizar el análisis realizado hasta aquí y aportar en el registro de aquellos espacios con una carga simbólica representativa para los residentes, se presenta en la Figura 8 la cartografía temática de los lugares-patrimonio que fueron destacados a lo largo del trabajo. Como se expresara, éstos han sido definidos por los antiguos y actuales habitantes de la localidad, constituyendo las representaciones y significaciones sociales condiciones relevantes para su determinación como tal. Se ha intentado aquí superar los abordajes tradicionales que fundamentan la se- lección patrimonial a partir de criterios rígidos, como pueden ser los atributos arquitectónicos, urbanísticos o paisajísticos. Si bien se considera que un lugar no constituye un mero punto georreferenciado, se concuerda con lo establecido por Nogué (2014), quien destaca que un lugar a pesar de no ser una simple localización, puede ser localizado en el territorio.

La cartografía temática se construyó a partir de dos variables clave, siendo el uso social de los componentes históricos el eje estructurador de ambas. Por un lado, se aplicó la categorización propuesta en el desarrollo de este trabajo, considerando aquellas funcionalidades: comercial y productiva, recreativa $y$ vinculadas a la prestación de servicios. En este caso, se adicionó un uso social mixto, teniendo en cuenta que algunos de los lugares-patrimonio mencionados, cumplían una doble función (comercial y recreativa, por ejemplo). Por otro lado, se consideró como segunda variable, los cambios y continuidades en dicha funcionalidad a lo largo del tiempo, reflejando su situación actual: sitios que permanecen con su uso original, los que han sufrido cambios, los que se encuentran inutilizados y aquellos lugares que son representativos desde su simbolismo, pero no guardan vestigio material alguno.

A partir de la lectura de la Figura 8, se puede afirmar que prevalen aquellos lugares-patrimonio vinculados a una funcionalidad comercial-productiva, seguidos por los que se relacionan con la prestación de servicios. Respecto a los sitios vinculados a la recreación, si bien son los que menor representatividad adquieren en términos cuantitativos, desde la subjetividad social dada por las historias de vida, adquieren protagonismo. A partir de los cambios y continuidades en dicho uso social a lo largo del tiempo, hoy en día prevalecen aquellos lugares con una funcionalidad diferente a la de sus orígenes. La mayoría de ellos, han sido refuncionalizados como vivienda de nuevos habitantes, como por ejemplo las antiguas dependencias ferroviarias. Seguidamente, se destacan los lugares que perdieron su uso social, como la antigua cancha de pelota paleta, de gran significancia para los locales, aunque en estado de abandono desde hace unos años. Por otro lado, también se resaltan aquellos lugares que configuran sitios históricos por su antigua funcionalidad, pero que no cuentan con ningún vestigio material, como puede ser el antiguo destacamento policial. Por último, con una menor representatividad, se pueden mencionar aquellos lugares-patrimonio que conservan su uso original, como el caso del único almacén de ramos generales 
existente o el Club Juventud Unida, que a pesar de funcionar de manera irregular, el fin para el que se lo utiliza continua siendo el mismo.

En términos generales, los lugares más valorados por los entrevistados y encuestados fueron aquellos vinculados al ferrocarril y los almacenes de ramos generales. El grupo poblacional conformado por los adultos y adultos mayores, son los que mayor anhelo y representaciones guardan en torno a éstos; ello en relación directa con las vivencias que construyeron a lo largo de su vida en la localidad. Asimismo, en los segmentos más jóvenes, aunque la valoración social fue más acotada, se lograron reconstruir y rescatar historias que han sido trasmitidas en el seno de cada una de las familias. Como se mencionara, la aprehensión se estos patrimonios específicos, en tanto construcciones sociales, se relaciona principalmente con el uso recreativo que albergaban, que excedía la función productiva o económica. Constituían nodos de encuentro obligado, en los que transitaba la vida cotidiana del pueblo, siendo además, un punto de conexión con el "afuera", ya sea a través del tren o a partir de los medios de comunicación (televisión, radio, telégrafo) que aquí se encontraban. De allí que estos lugares sean reivindicados en gran parte de los pueblos rurales bonaerenses y de la Argentina, como parte de procesos de puesta en valor turístico. Se (re) crean historias y se activan ciertos repertorios patrimoniales que intentan contar parte de estas expe-

FIGURA 8

LUGARES-PATRIMONIO DEFINIDOS POR LOS RESIDENTES DE LA LOCALIDAD, SEGÚN SU USO SOCIAL

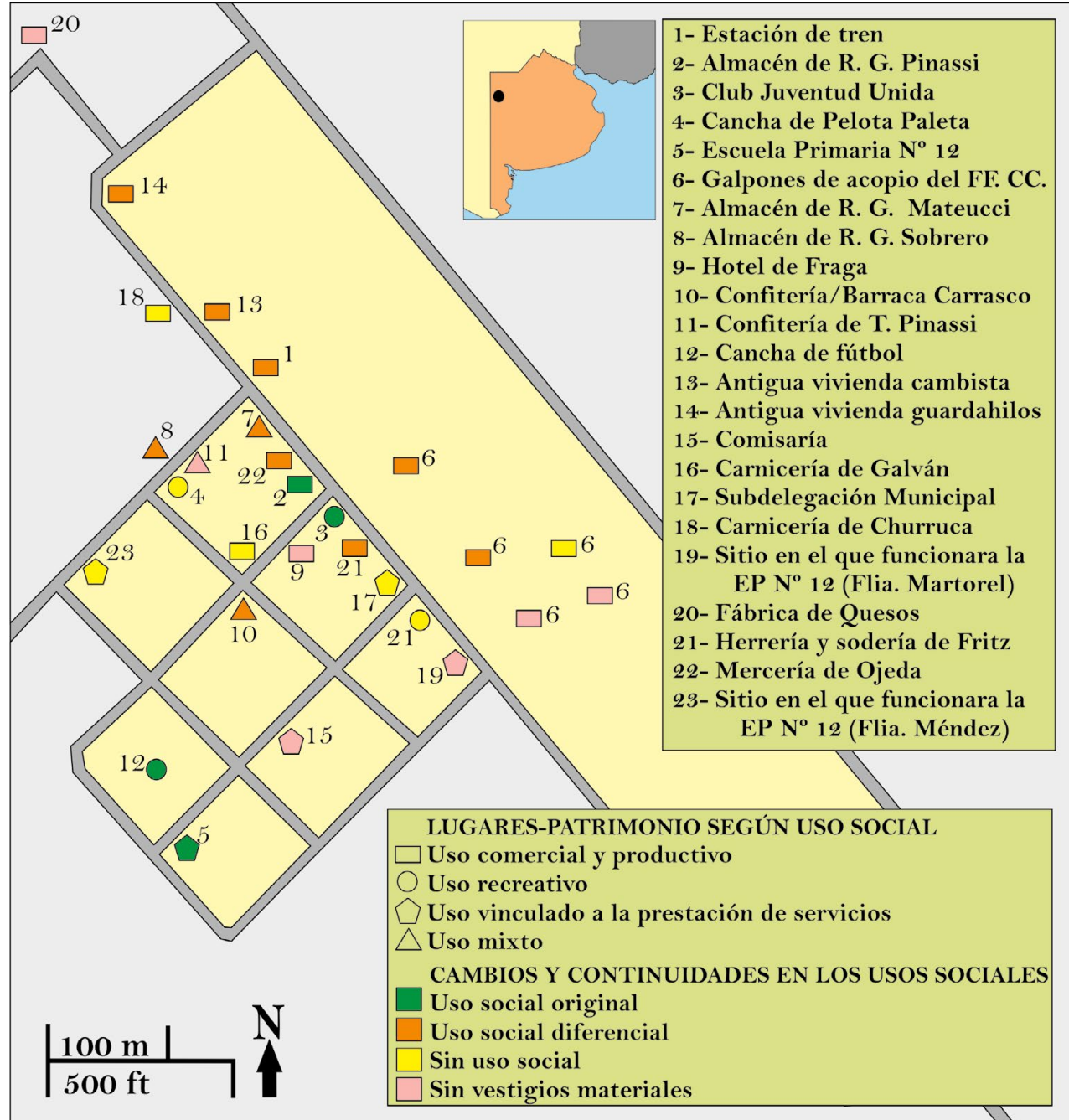

Fuente: Elaboración propia (2020). 
riencias cotidianas. Si bien cada sitio responde a discursos o mensajes particulares, según los actores que lleven a cabo la valorización patrimonial, este contexto se presenta como favorable y alentador para los lugares reivindicados en Sundblad por los pobladores. Cabrá articular ideas, intereses y recursos para poder incentivar su desarrollo y potenciar las propuestas, teniendo como eje la comunidad local, pilar clave para que prosperen las iniciativas.

\section{CONCLUSIONES}

En este trabajo se ha intentado contribuir en la comprensión de los lugares-patrimonio, a partir de los conceptos base que lo integran. Éstos estructuran espacios construidos socialmente a partir de una carga valorativa, conformada por significados, representaciones, vivencias y experiencias elaboradas por los sujetos en relación con el espacio de vida cotidiano. Se caracterizan, además, por ser configuraciones sociales que reflejan tensiones o conflictos, generados a partir de los procesos de los que forman parte, y en los que entran en juego relaciones de poder e intereses, según los actores implicados.

El presente trabajo aportó en el análisis de la configuración de los lugares-patrimonio en el caso del pueblo rural bonaerense de Sundblad, enfatizando en la mirada de los actuales y ex residentes de la localidad. Se coadyuvó a la construcción de la historia local, pudiendo identificar aquellos espacios devenidos en lugares-patrimonio, a partir de la carga simbólica atribuida por los propios habitantes, pero condicionados por determinados procesos socioterritoriales que operan en una escala extra local. Asimismo, se profundizó en el análisis de un lugar-patrimonio en particular, en el que se identificaron claramente ciertos puntos de tensión en relación a un mecanismo de patrimonialización impulsado. En un sentido general, la metodología desarrollada y las etapas de trabajo, estructuradas a partir de los usos sociales de los lugares históricos según la visión de los pobladores, al igual que la cartografía temática resultante, constituyen una propuesta alternativa que podría emplearse como parte de mecanismos participativos de gestión patrimonial en otras aglomeraciones.

A través de lo indagado, se puede afirmar que existe un fuerte sentido de pertenencia respecto al poblado en general y a los lugares identificados como patrimoniales en particular. A pesar de que algunos de éstos hoy en día resultan inexistentes desde su materialidad, en la memoria colectiva se guardan un cúmulo de historias vivenciadas por los habitantes. Parte del fin de este artículo fue echar luz sobre esos espacios vividos a fin de descubrir qué lugares adquieren protagonismo y se posicionan como referentes del devenir espacio-temporal para los propios residentes $y$, a su vez, comprender las problemáticas producidas en torno a algunos de ellos.

En relación a estos lugares-patrimonio identificados y al futuro de Sundblad, los residentes trazan un horizonte no muy alentador, que reflejan las características propias de la crisis del campo y los pequeños pueblos rurales. Estas características que se dan en la localidad analizada, son atributos compartidos por gran parte de los pueblos rurales de la Argentina: territorios estancados, en términos demográficos y de acceso a servicios básicos, pero en los que se vislumbran indicios de una revivificación que parece muy lejana. Como se destacara, la metodología aquí propuesta, pretende configurar un esquema que pueda aplicarse a otras localidades con características similares a las de Sundblad, teniendo como fin último descubrir e indagar aquellos lugares que forman parte del acervo patrimonial, definidos por los propios vecinos, y no por procesos impulsados desde otras escalas y por otros actores sociales, sin participación de los locales. Es decir, que constituye una herramienta para la documentación de aquellas historias vivenciadas, que debido a la carencia de registro, se van perdiendo en estos pueblos y parajes olvidados. La estructuración del esquema metodológico a partir de los usos sociales de los lugares-patrimonio, constituye una fortaleza, dado que éstos resultan análogos en su gran mayoría a otros emplazamientos. Las estaciones de tren, los almacenes de ramos generales, los clubes y escuelas rurales, configuran formas de espacio geográfico comunes en disímiles territorios rurales. Indagar acerca de los cambios y continuidades en la funcionalidad, en las representaciones y significaciones y en las prácticas sociales, favorece a comprender la lógica del medio rural en su conjunto, pero abordada desde otra arista, la de los lugares-patrimonio.

Por último, es importante destacar, que si bien el rol asignado a los residentes como sujetos sociales clave en la configuración de los lugares-patrimonio es fundamental, también es prioritario el apoyo de los actores gubernamentales, sobre todo en los pequeños pueblos rurales, dado que los recursos económicos resultan escasos, al igual que la capacidad de legitimación y respaldo institucional de ciertos organismos, necesaria para llevar a cabo los procesos de puesta en valor de los sitios en cuestión. 
En materia de caminos futuros de investigación vinculados al tema abordado, la articulación del concepto de lugar-patrimonio con los de identidad, memoria y comunidad, constituye un campo fecundo de

\section{NOTAS}

1 Si bien no es el objetivo de este artículo debatir acerca del concepto de pueblo rural, queremos expresar nuestro posicionamiento al respecto. A pesar de que existen diferentes criterios demográficos para determinar qué aglomeraciones configuran pueblos o ciudades, que para el caso de Argentina es de 2000 habitantes, en esta investigación se considera que lo rural excede este criterio rígido, relacionándose más con cuestiones vinculadas a la funcionalidad y la dinámica socioterritorial de las localidades, con las actividades productivas, con las costumbres propias de los residentes, su espacialidad y sociabilidad, entre otras características que hacen particulares a estos territorios.

2 Se entiende por espacio vivido patrimonial a "... aquel espacio vivido que se constituye a partir de los componentes del patrimonio cultural de una sociedad. Un espacio vivido puede devenir en espacio vivido patrimonial a través de su configuración sobre la base de un acervo cultural e histórico común, compartido por los habitantes de un determinado territorio" (Pinassi, 2019, p. 103).

3 "Elena Auguet nació el 22 de Julio de 1932... Desde niña se aficionó a la lectura. Casada con un ferro-

\section{REFERENCIAS BIBLIOGRÁFICAS}

Adamo, S. (2018). Movilidad espacial de la población rural y agrícola: perspectivas conceptuales-metodológicas. En H. Castro y M. Arzeno (coords.). Lo rural en redefinición. Aproximaciones y estrategias desde la geografía (pp. 171-204). Buenos Aires, Argentina: Biblos.

Arantes, A. (Org.) (1984). Produzindo o Passado. Estratégias de construção do patrimonio cultural. São Paulo, Brasil: Brasiliense.

Auguet, E. (1996). Tiempo de trenes. Argentina: edición del autor.

Barrios Barón, C. (2004). Tierra de pioneros. Junto a la Zanja de Alsina. Buenos Aires, Argentina: edición del autor. estudio que posibilitará debatir y reflexionar nuevas ideas acerca de este ámbito de análisis tan complejo.

viario vivió en la estación de Sundblad en el partido de Rivadavia. Allí se enamoró de los trenes y su entorno y comenzó a escribir sobre ellos. Publicó entonces 'Tiempo de Trenes'. Obtuvo premios literarios dentro y fuera de la provincia y participó en diversas antologías..." (http://escritoresderivadavia.com/autores/auguet-elena/, 2020).

4 La obra de Auguet, al igual que la de otros cuatro autores oriundos de Sundblad, ha sido reconocida bajo Ordenanza Municipal № 4.179/19, que denomina al pueblo rural como "Tierra de Escritores", realzando la figura no solo de estos personajes, sino también del aporte realizado a través de sus escritos. Para este artículo sólo se ha tenido en cuenta la obra de Elena Euguet, dado que es la única que ha adjetivado y analizado a la localidad de Sundblad en sus obras.

5 Por pedido de los entrevistados se establecen en este artículo solo las iniciales del nombre.

6 En sus inicios tuvo lugar en la primera vivienda que se encuentra en el ingreso al pueblo.

Barros, C. (2000). Reflexiones sobre la relación entre lugar y comunidad. Documentos Anales Geografía, (37), 81-94. Recuperado de: https://ddd.uab.cat/ pub/dag/02121573n37/02121573n37p81.pdf

Behling Oliveira, M. y Lemos Ribeiro, D. (2019). Patrimônios Afetivos: um novo recurso para o turismo em Morro Redondo-RS, Brasil. Revista Rosa dos Ventos - Turismo e Hospitalidade, 11 (4), 847-860.

Benedetti, A. (2017). Epistemología de la Geografía Contemporánea. Buenos Aires, Argentina: Universidad Virtual de Quilmes. 
Bertoncello, R. (1995). La movilidad territorial de la población: notas para la reflexión". Boletín Geográfico, (20), 47-61.

Bertoncello, R. (2008). Turismo y geografía: lugares y patrimonio natural-cultural de la Argentina. Buenos Aires, Argentina: Ciccus.

Bertoncello, R. (2010). Turismo y patrimonio, entre la cultura y el negocio. En M. Duarte y M. Ramos (Orgs.), Geografía, turismo e patrimonio cultural (pp. 33-53), San Pablo, Brasil: Annablume.

Bertoncello, R. (2017). Prólogo. En A. Pinassi, Patrimonio cultural, turismo y recreación. El espacio vivido de los bahienses desde una perspectiva geográfica (pp. 10-16). Bahía Blanca, Argentina: Ediuns.

Bertoncello, R. (2018). Turismo: expectativas, conflictos, contradicciones. La ciudad de Buenos Aires como destino turístico. En C. Milano y J. Mansilla, Ciudad de vacaciones. Conflictos urbanos en espacios turísticos (pp. 155-187). Barcelona, España: Pollen.

Cabrales Barajas, L. (2019). Salvaguarda de un patrimonio de la modernidad en Guadalajara: El zoológico de cemento. Investigaciones Geográficas, (100), 1-18. Recuperado de: http://www.investigacionesgeograficas.unam.mx/index.php/rig/article/ view/60020/53430

Castro, H. (2018). Lo rural en cuestión: perspectivas y debates sobre un concepto clave. En H. Castro y M. Arzeno (coords.). Lo rural en redefinición. Aproximaciones y estrategias desde la geografía (pp. 19-47). Buenos Aires, Argentina: Biblos.

Durham, E. (1998). Cultura, patrimonio, preservación. Alteridades, 8 (16), 131-136. Recuperado de: http:// biblioteca.ues.edu.sv/revistas/10800284-10.pdf

Florescano, E. (Comp.) (1993). El patrimonio cultural de México. México: Fondo de Cultura Económica.

García Canclini, N. (1989). Culturas híbridas: estrategias para entrar y salir de la modernidad. México: Grijalbo.

Giop, M. y Flores, F. (2017). Discursos patrimoniales y narrativas espaciales. Historias de una localidad lujanense (Buenos Aires, Argentina) (1864-2016). II Congreso Internacional de Geografía Urbana, Luján (Argentina): Universidad Nacional de Luján.
Hammen, M.; Lulle, T. y Palacio, D. (2009). La construcción del patrimonio como lugar: un estudio de caso en Bogotá. Antípoda, (8), 61-85. Recuperado de: https://www.redalyc.org/pdf/814/ 81411888004.pdf

Hiernaux, D. y Lindón, A. (Dir.) (2006). Tratado de geografía humana. México D.F., México: Anthropos.

Honorable Concejo Deliberante de Rivadavia (2014). Ordenanza Municipal № 3583/14. América (Buenos Aires, Argentina).

Honorable Concejo Deliberante de Rivadavia (2019a). Ordenanza Municipal № 4.179/19. América (Buenos Aires, Argentina).

Honorable Concejo Deliberante de Rivadavia (2019b). Ordenanza Municipal № 4.220/19. América (Buenos Aires, Argentina).

INDEC (Instituto Nacional de Estadística y Censos) (2001). Censo Nacional de Población, Hogares y Viviendas. Recuperado de: https://www.indec.gob. ar/micro_sitios/webcenso/provincias_2/provincias. asp

INDEC (Instituto Nacional de Estadística y Censos) (2010). Censo Nacional de Población, Hogares y Viviendas. Recuperado de: https://www.indec.gob. ar/indec/web/Institucional-Indec-BasesDeDatos

Lindón, A. (2006). Geografías de la vida cotidiana. En A. Lindón.; M. Aguilar y D. Hiernaux (Coords.), Lugares e imaginarios en la metrópolis (pp. 356400). Barcelona, España: Anthropos.

Lindón, A.; Hiernaux, D y Aguilar, M. (2006). De la espacialidad, el lugar y los imaginarios urbanos: a modo de introducción. En A. Lindón.; M. Aguilar y D. Hiernaux (Coords.), Lugares e imaginarios en la metrópolis (pp. 9-25). Barcelona, España: Anthropos.

Massey, D. (2004). Lugar, identidad y geografías de la responsabilidad en un mundo en proceso de globalización. Treballs de la Societat Catalana de Geografia, (57), 77-84. Recuperado de: https://publicacions.iec.cat/repository/pdf/00000019/00000025. pdf

Nogué, J. (1989). Espacio, lugar, región: hacia una nueva perspectiva geográfica regional. Boletín de la Asociación de Geógrafos Españoles, (9), 49-62. Recuperado de: https://dialnet.unirioja.es/servlet/ articulo?codigo $=1318196$ 
Nogué, J. (2014). Sentido del lugar, paisaje y conflicto. Geopolítica (s), Revista de estudios sobre espacio y poder, 5 (2), 155-163. Recuperado de: https://revistas.ucm.es/index.php/GEOP/article/view/48842

Pinassi, A. (2012). La arquitectura Italianizante como patrimonio cultural regional y potencial atractivo turístico recreativo. Caso de análisis: localidad de Sundblad (provincia de Buenos Aires, Argentina). $\checkmark$ Congreso Latinoamericano de Investigación Turística, San Pablo (Brasil): Universidad de San Pablo.

Pinassi, A. (2016). La configuración de un nuevo espacio turístico recreativo a través de la valorización del patrimonio cultural. El caso de Bahía Blanca (Tesis doctoral). Universidad Nacional del Sur, Bahía Blanca (Argentina).

Pinassi, A. (2017). Patrimonio cultural, turismo y recreación. El espacio vivido de los bahienses desde una perspectiva geográfica. Bahía Blanca, Argentina: Ediuns.

Pinassi, A. (2018). Conflictos en torno al patrimonio cultural de Ingeniero White (Bahía Blanca, Argentina). Cuadernos de Antropología Social, (48), 91110. Recuperado de: http://revistascientificas. filo.uba.ar/index.php/CAS/article/view/4100

Pinassi, A. (2019). Espacio vivido patrimonial: una mirada alternativa del patrimonio cultural desde la Ciencia Geográfica. Ería, Revista Cuatrimestral de Geografía, 1, 99-107. Recuperado de: https://www. unioviedo.es/reunido/index.php/RCG/article/ view/12931/0

Pinassi, A. y Silenzi, D. (2019). (Re) construcción del patrimonio cultural. De muelle portuario a paseo turístico recreativo. Ateliê Geográfico, 3 (2), 3050. Recuperado de: https://www.revistas.ufg.br/ atelie/article/view/56530

Prats, LL. (1997). Antropología y patrimonio. Barcelona, Argentina: Ariel.

Prats, LL. (1998). El concepto de patrimonio cultural. Política y Sociedad, (27), 63-76.

Prats, LL. (2005). Concepto y gestión del patrimonio local. Cuadernos de Antropología Social, (21), 1735. Recuperado de: https://www.redalyc.org/ pdf/1809/180913910002.pdf

Prats, LL. (2006). La mercantilización del patrimonio: entre la economía turística y las representaciones identitarias". PH Boletín del Instituto Andaluz del Patrimonio Histórico, (58), 72-80. Recu- perado de: https://www.iaph.es/revistaph/ index.php/revistaph/article/view/2176

Prats, LL. (2014). El carácter magmàtic del patrimoni etnològic. Revista D'Etnologia de Catalunya, (39), 152-159. Recuperado de: https://core.ac.uk/ download/pdf/39037917.pdf

Rosas Mantecón, A. (2005). Las disputas por el patrimonio. Transformaciones analíticas y contextuales de la problemática patrimonial en México. En N. García Canclini (Coord.), La antropología urbana en México (pp. 60-95). México: Fondo de Cultura Económica, Consejo Nacional para la Cultura y las Artes y Universidad Autónoma Metropolitana.

Sánchez, J. (2015). Despoblamiento de pequeñas localidades argentinas ¿Es responsable el tren? Documentos de Trabajo del Instituto del Transporte, (5), 1-83. Recuperado de: http://www.unsam.edu.ar/ institutos/transporte/publicaciones/Documento \%20N\%C2\%B0\%205_S\%C3\%A1nchez\%20FFCC\%20 y\%20poblaci\%C3\%B3n\%20de\%20peque\%C3 \%B1as\%20localidades.pdf

Sili, M. (2005). La Argentina rural: de la crisis de la modernización agraria a la construcción de un nuevo paradigma de desarrollo de los territorios rurales. Buenos Aires, Argentina: Ediciones INTA.

Sili, M. (2016). Un modelo para comprender la dinámica de los territorios rurales. El caso de la Argentina. Mundo Agrario, 17 (34), 1-20. Recuperado de: http://www.mundoagrario.unlp.edu.ar/ article/view/MAv17n34a03

Sili, M. (2019). La migración de la ciudad a las zonas rurales en Argentina. Una caracterización basada en estudios de caso. Población \& Sociedad, 26 (1), 90-119. Recuperado de: https://cerac.unlpam.edu. ar/index.php/pys/article/view/3352/3867

Sili, M.; Guibert, M. y Bustos Cara, R. (2015). Atlas de la Argentina rural. Buenos Aires, Argentina: Capital Intelectual.

Smith, L. (2011). El espejo patrimonial ¿ilusión narcisista o reflexiones múltiples?. Antípoda, (12), 3963. Recuperado de: https://revistas.uniandes. edu.co/doi/10.7440/antipoda12.2011.04

Tedesco, L. y Picardi, S. (2003). Historia económica del sector agropecuario argentino en los años '90. III Jornadas Agrarias y Agroindustriales. Buenos Aires, Argentina: UBA. 
Torres, F. (2011). Territorio y lugar: potencialidades para el análisis de la constitución de sujetos políticos. El caso de un movimiento de desocupados en Argentina. Geograficando, (2), 209-238. Recuperado de: http://www.memoria.fahce.unlp.edu. ar/art_revistas/pr.5099/pr.5099.pdf

Velho, G. (2013). Anthropology and cultural heritage. Vibrant: Virtual Brazilian Anthropology, 10 (1), 145-150.
Zusman, P. y Pérez Winter, C. (2018). Las áreas rurales y el patrimonio histórico-cultural. En $\mathrm{H}$. Castro y M. Arzeno (Coords.), Lo rural en redefinición. Aproximaciones y estrategias desde la geografía (pp. 231-252). Buenos Aires, Argentina: Biblos. 